\title{
Education, Demographics, and the Economy
}

\author{
Christian Jaag*
}

January 4, 2006

\begin{abstract}
This paper deals with two issues concerning the effects of population aging on education decisions in the presence of a PAYG pension system: We first analyze the effects of an aging population per se on individual skill choices and continuous education and the production structure. Second, we study the implications of postponed retirement, which is often proposed as a measure to cope with the economic challenges of increased longevity. Our study uses a dynamic general equilibrium framework with overlapping generations and probabilistic aging. The model allows for capital-skill complementarity in the production of final output. As a response to population aging, in a small open economy with a fixed interest rate, our first simulation shows that GDP is depressed due to an adverse effect on skill choice and labor supply. We then introduce postponed retirement as a potentially dampening policy measure due to its encouragement of human capital formation. However, since there is less private saving in this scenario, the overall effect on GDP is even worse than in the pure aging scenario.
\end{abstract}

*Institiute of Public Finance and Fiscal Law, University of St.Gallen, Varnbüelstrasse 19, CH-9000 St.Gallen, christian.jaag@unisg.ch. Financial support from the Swiss National Science Foundation under project no. 1214-066928 is gratefully acknowledged. 


\section{Introduction}

The purpose of this paper is to illuminate the macroeconomic relevance of education and human capital formation in an aging society. This topic has received much attention over the last years, mainly due to the expected sharp increase in the share of the retired over the working population (cf. figure 1). Moreover, older workers are leaving the labor force at younger and younger ages. ${ }^{1}$ This decline in labor force participation, which magnifies population trends, is due to specific characteristics of existing pension systems, which impose considerable negative accrual rates of pension wealth.

In order to compensate the adverse effects of the shift in the age structure on

\section{Figure 1}

Dependency ratio projections for Switzerland. The solid line shows the trend extrapolation, the dashed line a more pessimistic scenario

Source: BFS (2001)

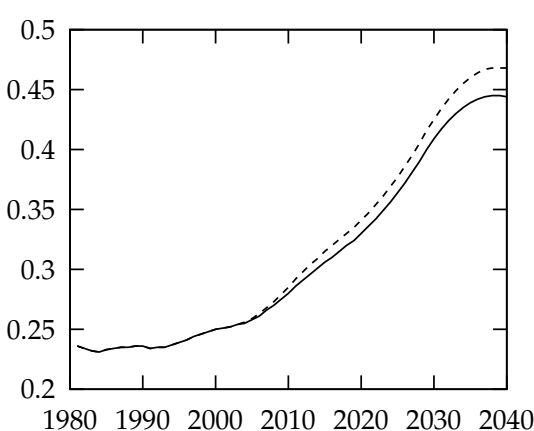

production, labor productivity of the working needs to increase or retirement must be postponed. ${ }^{2}$ We analyze the direct effect of a change in the age structure due to aging on the individuals' incentives to invest in education at the extensive margin. Indeed, aging itself strongly affects the skill structure of the workforce by changing the distribution of the workers' seniority. However, additional policy measures towards increased human capital investment would have to be put in place in order to maintain total employment and to assure the financial viability of existing pension systems. We show that postponed retirement raises educational attainment and human capital. However, it induces individuals to save less, which offsets these beneficial effects.

\footnotetext{
${ }^{1}$ An extensive source on retirement behavior in industrialized countries is Gruber and Wise (1999).

${ }^{2}$ Börsch-Supan (2003) argues that the decrease in the relative size of the economically active population cannot be balanced by higher capital intensity. Hence, the strengthening of human capital formation assumes high importance in the face of an aging population.
} 
In this paper, individuals' intensive and extensive education decision is studied, along with their intertemporal consumption choice and labor supply. To be able to simulate a concrete population and policy scenario, the model realistically reproduces (1) individual life-cycle wage and consumption profiles; (2) the skill composition in the labor force; (3) skill premia in wages; (4) the change in relative prices and the production structure due to an aging population and postponed retirement. We use an overlapping generations (OLG) approach in general equilibrium in order to be able to analyze intergenerational distribution effects.

The remainder of this paper is organized as follows: We first giv a short overview of the literature related to our subject. Based on the probabilistic aging approach, we then motivate our modeling of the production technology allowing for capitalskill complementarity. Third, we present a stylized model in order to highlight important economic effects showing up in our quantitative analysis. We then discuss the calibration of the model. Finally, we simulate the effects of aging and postponed retirement on key macro variables in an open economy setting.

\section{Related Literature}

In its complexity, the model relates to four strands of economic literature:

Education and the Economy Besides the vast literature on life-cycle human capital investment, which focuses on the intensive margin of education, there is a strand of literature concentrating on the extensive margin. ${ }^{3}$ This mostly empirical literature is concerned with self-selection of students into skill types according to ability types which affects estimates of occupational choice and the distribution of earnings. The first source is Roy (1951), which has received subsequent elaboration, e.g. by Heckman and Honoré (1990). Willis and Rosen (1979) and Heckman, Lochner, and Taber (1998) derive a theoretical model of the demand for college attendance and empirically show that expected lifetime earnings indeed influence the college attendance choice decisively. Due to the specific nature of their sample, there is no ability bias in the estimation of the enrollment function, a problem which is often encountered in the empirical assessment of the rate of return to education. Bils and Klenow (2000) argue that not only schooling

\footnotetext{
${ }^{3}$ Early references in the life-cycle human capital investment literature are Becker (1962) and Mincer (1974). Ben-Porath (1967) formulates a rigorous model which makes the analogy between human capital and investment in physical capital explicit. Weiss (1986) provides an extensive review of the theoretical literature, while Mincer (1997) reviews the empirical literature.
} 
leads to higher growth rates, such as in Barro (1991), but that there is also a reverse channel through which faster growth can induce more schooling by raising its effective return.

Overlapping Generations Economic models with overlapping generations of households provide a good basis for the analysis of fiscal policy and intertemporal macroeconomics. There are basically two strands of OLG literature: The one with a large number of generations and detailed life-cycle patterns pioneered by Auerbach and Kotlikoff (1987) with refinements by e.g. İmrohoroğlu, İmrohoroğlu, and Joines (1999) and Altig, Auerbach, Kotlikoff, Smetters, and Walliser (2001). The second strand bases upon the model by Ramsey (1928) with infinitely lived consumers. Blanchard (1985) introduces constant mortality hazard, which leads to potentially finite lifetimes but eternal youth. The model by Gertler (1999) introduces life-cycle behavior in this framework by allowing mortality only for the retired. We base our approach on its consequent enhancement by Grafenhofer, Jaag, Keuschnigg, and Keuschnigg (2005), who introduce probabilistic aging, which allows for mortality among young ages and thereby exhibits a closer approximation of the demographic structure.

Old-Age Provision There is a vast literature on the economics of old-age provision, arguing that the design of old-age provision considerably affects labor market participation and early retirement. ${ }^{4}$ Martín (2003) and Keuschnigg and Keuschnigg (2004) use computable general equilibrium (CGE) models to analyze how pension system reforms may be able to alleviate the expected financial difficulties of current PAYG systems. Lau and Poutvaara $(2000,2001)$ study the impact of social security incentives on human capital formation, arguing that actuarial fairness and a tight contributions-benefit link increase human capital along with an increase in the retirement age. İmrohoroğlu, İmrohoroğlu, and Joines (1995) derive optimal social security replacement rates and associated benefits by means of an applied general equilibrium model.

Demographic Transition The demographic transition in industrialized countries with lower fertility and higher life-expectancy poses challenges to pension systems and the economy as a whole (cf. e.g. Miles, 1999, Börsch-Supan and Winter, 2001, and Bovenberg and Knaap, 2005). Börsch-Supan (2003) argues that in order to finance the pension system, contribution and tax rates will have to rise, which reduces labor force participation of the younger cohorts and destabilizes

\footnotetext{
${ }^{4}$ Recent contributions are Börsch-Supan (2000), Mitchell and Phillips (2000), Crémer and Pestieau (2003), Bütler, Huguenin, and Teppa (2004), and Gruber and Wise (2005).
} 
the pension system even more. In a model with imperfect substitutability between less and more experienced workers, Rojas (2005) shows that the effects of aging are less hazardous than with perfectly substitutable workers. Also, Conesa and Krueger (1999) consider heterogeneous agents and their impact on the political support for a funded pension system.

Besides its adverse effects on the pension system, population aging may induce individuals to invest more in education and postpone retirement. ${ }^{5}$ The contribution of this paper is an analysis of these effects by means of a model featuring a realistic production structure with differentiated labor inputs and coherent education decisions in a general equilibrium model with overlapping generations based on probabilistic aging, as developed in Grafenhofer, Jaag, Keuschnigg, and Keuschnigg (2005) and Jaag, Keuschnigg, and Keuschnigg (2005).

\section{Capital-Skill-Complementarity}

Many life-cycle models with overlapping generations, such as the original Auerbach and Kotlikoff (1987) model, but also e.g. Altig, Auerbach, Kotlikoff, Smetters, and Walliser (2001) assume labor to be homogeneous. Recently, heterogeneous labor has been introduced in various ways: Heckman, Lochner, and Taber (1998) use labor which is differentiated by skill level, while Rojas (2005) uses a labor market characterized by imperfect substitutability between less and more experienced workers, hence introducing a vertical differentiation of labor. In our model, the individuals' discrete education choice leads to a partition of the working population into different skill classes, which is mirrored on the production side, where the firms' technology uses as inputs differentiated labor and capital, hence giving rise to a horizontal differentiation of labor. For simplicity, we assume that the experience of workers does not alter their type of labor.

The surge in skill-biased information technology during the 1990s, which coincided with a rise in the wages of skilled workers relative to those of unskilled workers, suggests that various kinds of labor are of different substitutability with capital. The first evidence of this phenomenon is due to Griliches (1969),

\footnotetext{
${ }^{5}$ Swanson and Kopecky (1999), de la Croix and Licandro (1999), Kalemli-Ozcan, Ryder, and Weil (2000), Boucekkine, de la Croix, and Licandro (2002, 2002a), Kalemli-Ozcan (2002), Huang, Fulginiti, and Peterson (2003), Soares (2005), Echevarría (2004), and Ferreira and de Abreu Pessôa (2005) consistently find that human capital accumulation and economic growth are increased via these channels - possibly even without changes in the social security system.
} 
who refers to his finding that capital and skilled labor are more complementary as inputs than are capital and unskilled labor as the capital-skill complementary hypothesis. The hypothesis has received broad attention in the macroeconomic literature, where evidence in its favor has important implications on how to specify aggregate production in theory, but also in reassessing the robustness of existing empirical findings. Quantitative implications of the hypothesis are studied e.g. by Duffy, Papageorgiou, and Perez-Sebastian (2004) who find only weak evidence in support of it, however. The hypothesis has also been tested in many microeconomic studies with firm and industry-level data. For a representative sample of such studies cf. Hamermesh (1993), who concludes that there is strong evidence for capital-skill complementarity. However, he cautions that many of the studies that disaggregate the workforce by demographic group exclude capital as a productive input due to the lack of a reliable measure of the capital stock. The assumption of competitive markets allows early studies to proxy variations in the capital stock by variations in the rates of return. More recent studies refrain from this assumption and explicitly include the stock of capital in their analysis (cf. Duffy, Papageorgiou and Perez, 2004).

Goldin and Katz (1998) argue that physical capital and skills have not always been viewed as relative complements: In an earlier era, the transformation from skilled artisan shops to factories involved the substitution of physical capital and unskilled labor for highly skilled labor - precisely the opposite of what is hypothesized to be happening today. This suggests that capital-skill complementarity may be a transitory phenomenon: In a country's development process, skilled labor may change from being well substitutable with capital and unskilled labor to being highly complementary to these two inputs. In order to account for this, recent studies consider panel data over long periods of time (e.g. Duff, Papageorgiou and Perez, 2004) or split the full country sample into subsamples of similar development (e.g. Papageorgiou and Chmelarova, 2003). A consistent finding also supported by Galor and Weil (2000) is that the capital-skill complementarity is especially strong at the beginning of a development process and may fade out when a technology becomes widely adopted.

The observed increase in the skill premium during the 1990s in developed countries may be due to skill-biased technological change, as is brought forward e.g. by Acemoglu (1998), who argues that an increase in the supply of skills reduces the skill premium in the short run, but induces biased technological change and hence increases the skill premium in the long run. Krusell, Ohanian, Rios-Rull, 
and Violante (2000) challenge this view in an empirical study, where they find that with capital-skill complementarity, changes in observed inputs in the aggregate production function alone account for most of the variations in the skill premium.

To our knowledge, the approach in this paper is the first to employ a production technology with potentially many types of labor and capital-skill complementarity in a general equilibrium OLG framework. We start by describing a stylized model exemplifying the main channels, through which the shocks in the scenarios affect economic outcomes in our model. The according building blocks of the actual CGE model are described in the appendix.

\section{Illustrative Simple Model}

As discussed in Jaag, Keuschnigg, and Keuschnigg (2005), the human capital accumulation process over the lifecycle can be analyzed independently of other life-cycle choices, such as optimum consumption and leisure. Therefore, in this section, we concentrate on extensive and intensive education decisions and on the specifics of the production technology.

\subsection{Production Technology}

For an illustration of capital-skill complementarity in production, consider the simple production function

$$
Y=f\left(K, L^{1}, L^{2}\right)=\left(K+L^{1}\right)^{\vartheta}\left(L^{2}\right)^{1-\vartheta}
$$

where capital $K$ and unskilled labor $L^{1}$ are perfect substitutes and have unit elasticity of substitution with skilled labor $L^{2}{ }^{6}$ The ratio of the marginal products of skilled to unskilled labor, and accordingly the relative wage of high skilled labor, is

$$
\frac{w^{2}}{w^{1}}=\frac{f_{L^{2}}}{f_{L^{1}}}=\frac{1-\vartheta}{\vartheta} \frac{K+L^{1}}{L^{2}} .
$$

\footnotetext{
${ }^{6}$ Note that in order to have capital-skill complementarity with this specific functional form, deviating from the functional form in (25), capital has to be nested together with unskilled labor.
} 
This will determine human wealth in the respective skill classes and govern the extensive education decision at the beginning of the life-cycle. It also constitutes the relative labor demand in figure 4 .

\subsection{Human Capital Production}

For the illustrative purpose of this section, we consider two different types of human capital $s \in\{1,2\}$, which constitute skilled and unskilled labor, respectively. Low-skilled productivity is denoted by $\theta^{1}$, while high-skilled productivity is $\theta^{2}$. Time and individual ability are the only inputs of human capital production (cf. figure 2): Over her life-cycle, an individual spends her time on education up to date $e$. Then, she works with exogenously given intensity until retirement at date $R$.

We assume that individual ability $\iota$ is relatively more important in acquiring

Figure 2

An individual's activity over the life-cycle.

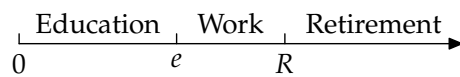

high-skilled human capital. These characteristics of human capital accumulation are formalized as

$$
\begin{aligned}
& \theta_{\iota}^{1}=\omega e_{\iota}^{1}, \\
& \theta_{\iota}^{2}=\iota e_{\iota}^{2} \quad \iota \in[0,1] .
\end{aligned}
$$

Note that for simplicity, $\theta^{1}$ is independent of $\iota^{7}$ Individuals maximize their human capital, i.e. their lifetime earnings. The problem of an individual with ability $\iota$ is therefore to choose the type of human capital $s_{\iota}$ and the optimal education time spent on its accumulation $e_{\iota}^{s}$, given the retirement date $R_{\iota}$ and the wage-rate $w^{s}$ per unit of human wealth, such that

$$
\left\{s_{\iota}, e_{l}^{s}\right\}=\arg \max _{\left\{\tilde{s}_{\iota}, \tilde{e}_{l}\right\} \in\{1,2\} \times\left[0, R_{\iota}\right]} H_{\iota}^{s}=\int_{e_{l}^{\tilde{s}}}^{R_{\iota}} \theta_{\iota}^{\tilde{s}} w^{\tilde{s}} d \tau .
$$

\footnotetext{
${ }^{7}$ In the simulated model, ability does not enter the human capital production function, but is a determinant of the cost of acquiring a certain skill level. This leads to a clear stratification of ability types in both formulations. In order to keep this illustrative example simple, we abstain from introducing type-dependent costs of education - apart from the opportunity costs of time. This is similarly done, e.g. in Cervellati and Sunde (2005) and Razin and Sadka (2001).
} 
The benefit of a longer education period is an increase in productivity during the working period. The cost consists of a shorter work life. For any individual of ability $\iota$ there is a unique time investment, which maximizes lifetime earnings from any type of human capital,

$$
\begin{aligned}
& e_{\iota}^{1}=\arg \max _{\tilde{e}_{l}^{1}}\left(R-\tilde{e}_{\iota}^{1}\right) \omega \tilde{e}_{\iota}^{1} w^{1}=e^{1}=\frac{R}{2}, \\
& e_{\iota}^{2}=\arg \max _{\tilde{e}_{l}^{2}}\left(R-\tilde{e}_{\iota}^{2}\right) \iota \tilde{e}_{\iota}^{2} w^{2}=e^{2}=\frac{R}{2} .
\end{aligned}
$$

Since ability enters both benefit and cost symmetrically, there are no differences in education among individuals of different ability. The resulting skill levels are therefore, by (2) and (3),

$$
\begin{aligned}
& \theta_{\iota}^{1}=\theta^{1}=\omega \frac{R}{2}, \\
& \theta_{\iota}^{2}=\iota \frac{R}{2} .
\end{aligned}
$$

Hence, optimum skill acquisition is proportional to the expected length of the working period, and only $\theta_{l}^{2}$ depends on the ability of the individuals in that skill group.

\subsection{Extensive Education Decision}

The type of human capital an individual chooses to acquire - measured as the sum over all lifetime earnings - results from a comparison of the respective levels of human wealth

$$
\begin{aligned}
& H^{1}=\int_{e^{1}}^{R} \theta^{1} w^{1} d \tau=\left(\frac{R}{2}\right)^{2} \omega w^{1}, \\
& H_{\iota}^{2}=\int_{e^{2}}^{R} \theta_{\iota}^{2} w^{2} d \tau=\left(\frac{R}{2}\right)^{2} \iota w^{2} .
\end{aligned}
$$

Individuals with higher ability have a comparative advantage in the acquiring of skills, and the human capital of those investing in skills increases monotonically in the ability parameter, cf. figure 3. 
Figure 3Discrete Choice between two skill groups.

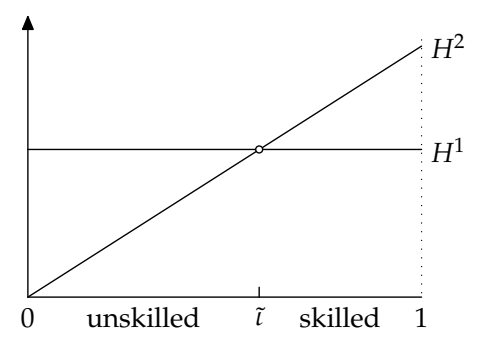

An individual is indifferent between acquiring low-skilled and high-skilled human capital iff

$$
H^{1}=H_{\tilde{l}}^{2} .
$$

Hence, using (6) and (7), the pivotal (indifferent) worker type $\tilde{\iota}$ is determined by

$$
\tau=\omega \frac{w^{1}}{w^{2}} .
$$

The relative size of the two skill classes is determined by the relative wage, which itself by (1) depends on the skill structure in the economy. The total number of efficiency units in each skill class is given by the employment duration, $R-e^{S}$, times the number of workers times their human capital. Assuming skills to be distributed uniformly over the unit interval, $\iota \sim U(0,1)$, and normalizing the total number of workers to unity, the number of low skilled workers is equal to $N^{1}=\tilde{\imath}$. The number of high skilled workers is accordingly $N^{2}=1-\tilde{\imath}$. The size of the two labor forces in efficiency units is then given by

$$
\begin{aligned}
& L^{1}=\left(R-e^{1}\right) N^{1} \theta^{1}=\left(\frac{R}{2}\right)^{2} \tilde{\iota} \omega, \\
& L^{2}=\left(R-e^{2}\right) \int_{\tau}^{1} \theta_{\iota}^{2} d \iota=\left(\frac{R}{2}\right)^{2}\left(\frac{1}{2}-\frac{1}{2} \tau^{2}\right) .
\end{aligned}
$$

Relating (9) to (6), we see that the total wage bill for unskilled labor, $w^{1} L^{1}$ just equals total human capital $H^{1} N^{1}$. Substituting (8) for $\tilde{\imath}$, we get

$$
\begin{aligned}
\frac{L^{2}}{L^{1}} & =\frac{1}{2 \omega}\left(\frac{1}{\tilde{\iota}}-\tilde{\iota}\right) \\
& =\frac{1}{2}\left(\frac{1}{\omega^{2}} \frac{w^{2}}{w^{1}}-\frac{w^{1}}{w^{2}}\right) .
\end{aligned}
$$

This yields the increasing relative labor supply curve in figure 4 below. 


\subsection{Equilibrium}

The equilibrium is characterized by a stratification of individuals according to (11), which determines the relative size of the two skill classes, wages and intensive education levels. Inserting (1) and (9)/(10) into (8), we implicitly get the equilibrium pivotal worker type

$$
\tilde{\iota}=\omega \frac{\vartheta}{1-\vartheta} \frac{\left(\frac{R}{2}\right)^{2}\left(\frac{1}{2}-\frac{1}{2} \tau^{2}\right)}{K+\left(\frac{R}{2}\right)^{2} \tilde{\iota} \omega}
$$

as a function of the relative importance of the two labor types in production $\vartheta$, the level of the capital stock $K$, the retirement date $R$, and the relative productivity of time in educational production $\omega$.

Since the demand for labor is - by the capital-skill complementarity - tightly linked to the capital stock, we first analyze the equilibrium reaction of education to changes in capital. The responses of intensive and extensive education to an increase in the capital stock are

$$
\begin{aligned}
& \frac{d e^{1}}{d K}=\frac{d e^{2}}{d K}=0 \\
& \frac{d \tilde{\imath}}{d K}=-\frac{1}{\frac{K}{\imath}+\omega\left(\frac{R}{2}\right)^{2} \frac{2-\vartheta}{1-\vartheta}}<0 .
\end{aligned}
$$

Educational effort at the intensive margin is not influenced by a change in the capital stock since the costs of education consist only of foregone earnings and a change in marginal productivity affects both costs and benefits equally. Figure 4 displays the effect of a decrease in the capital stock at the extensive margin. As long as the relative supply of low and high skilled labor is unchanged, by the complementarity of capital and skilled labor, the relative demand for skilled labor shifts to the left, moving the equilibrium from point (a) to (b). The resulting decrease in the skill premium induces less workers to acquire skills, which shifts the relative supply for skilled labor to the left, leading to the final equilibrium in point (c).

An increase in the retirement age affects education both at the intensive and the extensive margin. We find that in equilibrium the comparative static effects of 


\section{Figure 4}

Dynamic effects of capital-skill complementarity.

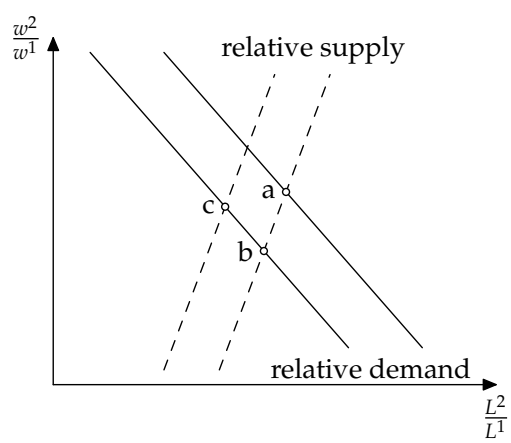

postponed retirement on extensive and intensive education are

$$
\begin{aligned}
\frac{d e^{1}}{d R} & =\frac{d e^{2}}{d R}=\frac{1}{2}>0, \\
\frac{d \tilde{\iota}}{d R} & =\frac{\frac{\vartheta}{1-\vartheta} \frac{R}{2}-\tilde{\iota}^{2} \frac{2-\vartheta}{1-\vartheta} \frac{R}{2}}{\frac{2 K}{\omega}+2 \iota \frac{2-\vartheta}{1-\vartheta}\left(\frac{R}{2}\right)^{2}} \lesseqgtr 0, \\
& \Leftrightarrow \tau \gtreqless \sqrt{\frac{\vartheta}{2-\vartheta}} .
\end{aligned}
$$

Educational effort is increased by a prolongation of the redemption period. At the extensive margin, education increases as long as the relative size of the high skilled workforce is below a certain threshold, which is determined by the relative importance of capital and low skilled labor and high skilled labor in the production process: With a high importance of skilled labor, postponed retirement will likely increase its share.

Relative supply remains unchanged initially, as both labor forces grow in parallel. According to (1), relative demand shifts to the left, moving the equilibrium from (a) to (b) in figure 5. Again, the resulting decrease in the skill premium induces less workers to acquire skills, which shifts the relative supply for skilled labor to the left. Considering (9) and (10), the size of this shift depends on the initial relative sizes of the two workforces. The shift in relative supply leads to the final equilibrium in point (c). Depending on the parameter constellation, the relative wage has risen or fallen in the new stationary equilibrium. 


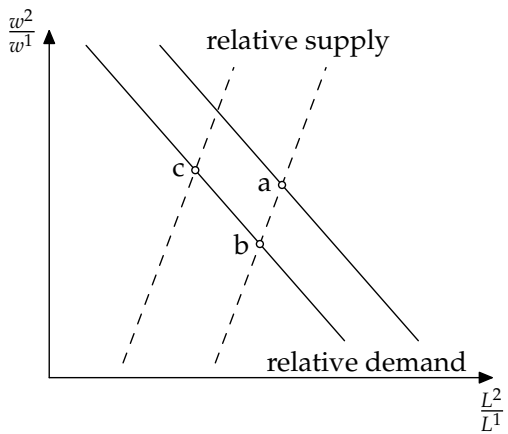

\section{Calibration}

Our simulations are based on the model developed by Jaag, Keuschnigg, and Keuschnigg (2005), incorporating probabilistic aging and frictional labor markets. ${ }^{8}$ We calibrate the model to stylized data of Switzerland in 2000. Table 5.1 states key parameters characterizing preferences and technology. The choice of the most important parameters is detailed in the following sections by referring to the relevant literature.

Studies on the depreciation rate of human capital range between $1 \%$ and $12 \%$ (cf. Heckman, 1976, Haley, 1976, Lechner and Vazquez-Alvarez, 2005, and the review by Browning, Hansen, and Heckman, 1999). In the applied literature, very low values are used: Zero by Heckman, Lochner, and Taber (1998) and 0.025 by Perroni (1995). We employ a value of 0.05 . Following the literature, we calibrate the depreciation rate of physical capital to 0.1 .

\subsection{Mortality and Transition Probabilities}

Individual aging occurs not deterministically (cf. appendix 8.1): In every period, there is a probability of aging $\omega^{a}$. There is also an age-group specific mortality probability $1-\gamma^{a}$. Let $N^{a}$ denote the number of individuals in age group $a$. A tilde indicates the decomposition in annual cohorts, such that $N^{a} \equiv \tilde{N}^{t}$. For simplicity, we consider a demographic stationary state and ignore time indices in this section. We further assume that aging parameters are equal across skill

${ }^{8}$ The feature of frictional labor markets is not explicitly exploited in our simulations, however. 
Table 5.1

Taste and technology parameter calibration.

\begin{tabular}{lc}
\hline Real interest rate $R$ & 1.050 \\
Capital depreciation rate $\delta^{K}$ & 0.100 \\
Skill depreciation rate $\delta^{S}$ & 0.050 \\
Subjective discount factor $\beta$ & 0.997 \\
Cost share of goods invested in education $\varsigma$ & 0.250 \\
Elasticity of intertemporal substitution $\sigma$ & 0.500 \\
Semi-elasticity of discrete skill choice $\varepsilon^{d}$ & 0.100 \\
Training elasticity with respect to training returns $\varepsilon^{e}$ & 0.300 \\
Labor supply elasticity $\varepsilon^{l}$ & 0.400 \\
Capital - low skill elasticity of substitution $\sigma^{K, L^{1}}$ & 1.600 \\
Capital - medium skill elasticity of substitution $\sigma^{K, L^{2}}$ & 1.000 \\
Capital - high skill elasticity of substitution $\sigma^{K, L^{3}}$ & 0.600 \\
Social security contribution $\tau^{W}$ & 0.080 \\
\hline Notes: The training and labor supply elasticities are $\varepsilon^{i} \equiv \varphi_{i}^{\prime} /\left(i \varphi_{i}^{\prime \prime}\right)$ for \\
$i \in\{e, l\}$, where $\varphi$ is a cost function, cf. (20). Technology as in $(25)$, \\
social security contributions are relative to gross wage income, such \\
that $\tau^{W} w_{t}^{a} l_{t}^{a} \tilde{\theta}_{t}^{a}=-z_{t}^{a} W$, where $w_{t}^{a} l_{t}^{a} \tilde{\theta}_{t}^{a}$ is average gross wage income.
\end{tabular}

groups. Setting $\omega^{a}=0$ implies that an aging event occurs with probability one in each period, leading to $\tilde{N}^{t}=\tilde{\gamma}^{t-1} \tilde{N}^{t-1}$. The concept of an age group thus becomes identical with a cohort, where age $t$ is measured by time since birth. Taking age-dependent survival rates $\tilde{\gamma}^{t}$ from official mortality tables, the cohort composition of the population in a demographic steady state can be constructed. Recursively applying $\tilde{N}^{t}=\tilde{\gamma}^{t-1} \tilde{N}^{t-1}$ yields the size of cohort $t$ relative to the size of a new cohort. Summing up over all cohorts fixes the size of the new cohort compared to total population size $N$,

$$
\tilde{N}^{t}=\tilde{N}^{1} \prod_{s=1}^{t-1} \tilde{\gamma}^{s}, \quad \tilde{N}^{1}=N / \sum_{t=1}^{T} \prod_{s=1}^{t-1} \tilde{\gamma}^{s} .
$$

Taking a total length of life of $T$ years, and based on actual survival rates, we have thus found the stationary decomposition of the population into a total of $T$ cohorts. Using the population decomposition indicated in table 5.2, each age groups contains several cohorts,

$$
N^{a}=\sum_{t=\alpha_{a}}^{\alpha_{a+1}} \tilde{N}^{t}
$$


Given that the instantaneous probability of staying in the current age-group is $\omega^{a} \gamma^{a}$, the expected duration in group $a$ is

$$
\alpha_{a+1}-\alpha_{a}=1 /\left(1-\omega^{a} \gamma^{a}\right)
$$

where $\alpha_{a}$ denotes the time when age-group $a$ is entered. The chosen age group decomposition of the actual population corresponds to a life-cycle history where an agent spends exactly the average duration in each age period. One can thus recover the demographic parameters of the model from our knowledge of aggregated population data $N^{a}$ and duration in group $a$. In a demographic steady state, each age group must fulfill the restriction

$$
\left(1-\gamma^{a} \omega^{a}\right) \cdot N^{a}=\left(\gamma^{a-1}-\gamma^{a-1} \omega^{a-1}\right) \cdot N^{a-1} .
$$

At this stage, one knows $N^{a}$ from aggregated population data and $\gamma^{a} \omega^{a}$ from the age group duration as implied by the chosen aggregation. The only unknown in (12) is $\gamma^{a-1}$, which is easily solved for all groups except the last one. For the last group, $\gamma^{A}$ follows directly from (12) on account of the restriction $\omega^{A}=1$. For all age groups $a<A, \gamma^{a}$ can now be recovered recursively.

Individuals enter our model at age 20 . We exclude ages $0-20$ from the analysis for two reasons: First, in our model setting, the extensive schooling decision as described in section 8.3 in the appendix is considered to make up the initial condition for on-the-job training, and second, the actual survival function cannot be easily approximated as the mortality hazard is non-monotonous.

Table 5.2 shows our decomposition of the population from ages 20 to 90 . The aging pattern corresponds to a life-cycle biography $\alpha=(20,30,40,50,60,70,80,85)$, which serves as an aggregation key. It allows for a statement about the size and law of motion of the various age groups. The parameters $\gamma^{a}$ and $\omega^{a}$ and the inflow into age-group $1, N_{t+1, t+1}^{1}$, are chosen such that the stationary solution to (16)-(19) in the appendix corresponds to line 3 in table 5.2.

\subsection{Intertemporal Substitution}

In the literature, much effort has been devoted to accurately pin down the value of the rate of intertemporal substitution. On the one hand, macroeconomists use 
Table 5.2

Demographic and life-cycle parameters.

\begin{tabular}{|c|c|c|c|c|c|c|c|c|}
\hline Age groups & 1 & 2 & 3 & $\overline{4}$ & 5 & 6 & 7 & 8 \\
\hline Cohorts & $20-29$ & $30-39$ & $40-49$ & $50-59$ & $60-69$ & $70-79$ & $80-84$ & $85-89$ \\
\hline Data $N^{a} / N$ & 0.168 & 0.222 & 0.192 & 0.168 & 0.120 & 0.089 & 0.025 & 0.016 \\
\hline Model $N^{a} / N$ & 0.179 & 0.177 & 0.175 & 0.168 & 0.148 & 0.107 & 0.031 & 0.016 \\
\hline Labor prod. $\tilde{\theta}^{1, a}$ & 1.000 & 1.189 & 1.237 & 1.121 & 0.942 & 0.000 & 0.000 & 0.000 \\
\hline Labor prod. $\tilde{\theta}^{2, a}$ & 1.299 & 1.490 & 1.641 & 1.705 & 1.609 & 0.000 & 0.000 & 0.000 \\
\hline Labor prod. $\tilde{\theta}^{3, a}$ & 1.431 & 2.388 & 2.663 & 2.921 & 2.462 & 0.000 & 0.000 & 0.000 \\
\hline Prob. $1-\gamma^{a}$ & 0.001 & 0.001 & 0.004 & 0.012 & 0.028 & 0.042 & 0.096 & 0.200 \\
\hline Prob. $1-\omega^{a}$ & 0.099 & 0.099 & 0.096 & 0.089 & 0.074 & 0.061 & 0.115 & 0.000 \\
\hline Factor $\Omega^{a}$ & 1.026 & 1.036 & 1.046 & 1.053 & 1.056 & 1.085 & 1.102 & 1.000 \\
\hline Propens. $1 / \Delta^{a}$ & 0.039 & 0.044 & 0.051 & 0.062 & 0.078 & 0.104 & 0.161 & 0.220 \\
\hline
\end{tabular}

Notes: $\tilde{\theta}^{s, a}$ is average productivity, $1-\gamma^{a}$ probability of dying, $1-\omega^{a}$ probability of aging, $\Omega^{a}$

magnification factor reflecting increase in mortality, $1 / \Delta^{a}$ marginal propensity to consume.

Data sources: BFS $(2001,2004)$ and own calculations.

a large value in general, reflecting a common view that a high degree of intertemporal substitution is more consistent with aggregate data considering dynamic macroeconomic models. In their seminal paper, Kydland and Prescott (1982) calibrate it to 0.66, and Lucas (1990) argues that an elasticity of 0.5 appears too low when confronted with macro data. Laitner and Silverman (2005) estimate it to be as high as 0.87. Also, Weil (1989) finds that in order match growth and business cycle facts the intertemporal rate of substitution is required to be close to unity. In an influential paper Hall (1988) shows that consumption growth is completely insensitive to changes in interest rates and, therefore, intertemporal elasticity is close to zero. Guvenen (2003) argues that this apparent contradiction arises from ignoring heterogeneity across individuals with respect to stock market participation and wealth. The properties of aggregate variables directly linked to wealth, such as investment and output are entirely determined by high-elasticity stockholders, while aggregate consumption, which is more evenly distributed across households, uncovers the low-elasticity of most households. In accordance with the literature on life-cycle modeling, we calibrate the elasticity of intertemporal substitution to 0.5 and check for robustness with values of 0.3 and 0.7 . 


\subsection{Skill Structure and Labor Market}

In order to account for the established difference between labor of various skill levels in their substitutability with capital, we use a nested CES production function commonly used in the relevant empirical literature; specific to our setting is the inclusion of more than two skill classes. Every differentiated input factor in the production function makes up for an input level in the nesting structure, as shown in figure 12 below. We concentrate on the analysis of three differentiated skill classes, which is a realistic reproduction of the education structure in Switzerland .

With the skill choice given by (24) in the appendix, the cost parameter $\xi^{S}$ of extensive education is calibrated using

$$
\xi^{s}=\frac{\Delta V^{s}}{\exp \left(\frac{\Gamma\left(v^{s}\right)}{\varepsilon^{D}}\right)}
$$

where $\Gamma\left(v^{s}\right)$ can be recovered from the skill distribution of the 20 years old in the population. As to the extensive skill choice, Heckman, Lochner, and Taber (1998) find that an increase in college tuition of $\$ 1000$ (or - equivalently - a decrease in the present value of after-tax earnings) decreases the probability of attending college by about 0.08 . This estimate is slightly higher than the estimate by Kane (1994) who finds an according decrease by 0.05 (cf. also Dupor, Lochner, Taber, and Wittekind, 1996). There is no clear direct empirical evidence on the effect of wage differentials on the extensive education decision. Topel (1999), Card and Lemieux (2000), and Cunha, Heckman, and Navarro (2005) suggest that teenagers use information on the wage gaps between different attainment levels to evaluate the size of their own future returns to schooling. Since there are many more factors influencing high school and university attendance, such as credit constraints and uncertainty about future earnings, we use a value of 0.1 for the semi-elasticity of the extensive skill choice with respect to differences in indirect utility.

\section{Figure 5.6}

Skill distribution in the Swiss population, 2000.

Source: BFS (2004)

\begin{tabular}{rrrr} 
Skill class & ISCED & Size & Inc. share \\
\hline 1 & $1 / 2$ & $19 \%$ & $12 \%$ \\
2 & $3 / 4$ & $54 \%$ & $50 \%$ \\
3 & $5 / 6$ & $27 \%$ & $38 \%$
\end{tabular}


The three skill classes refer to individuals whose highest level of education is secondary I, secondary II and tertiary, respectively. Figure 5.6 shows the according $\mathrm{ISCED}^{9}$ levels of our skill classes along with their relative population- and labor income shares. The skill class and age group specific productivity parameter $\theta$ is calibrated using wage data from Switzerland, 2000. The shapes of individual wage profiles are displayed in figure 7 .

The income share of capital is chosen to be 0.35 (cf. İmrohoroğlu, İmrohoroğlu,

\section{Figure 7}

Wageprofiles of high, medium, and low skilled workers.

Source: BFS (2004), own computations

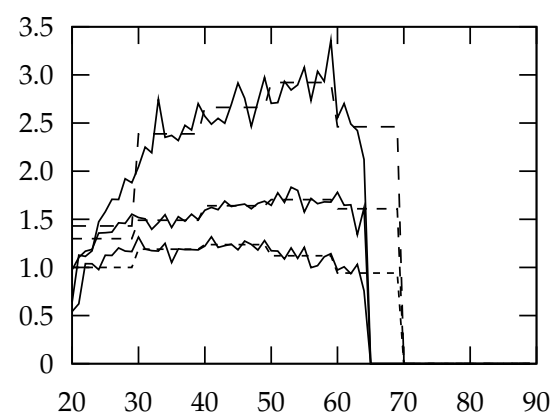

and Joines, 1995, and Conesa and Krueger, 1999, who choose 0.36). The empirical evidence on the static labor supply elasticity is reviewed by Hansson and Stuart (1985) and Blundell and MaCurdy (1999). The latest, most advanced studies yield estimates of the uncompensated wage elasticity of labor supply between 0.05 and 0.12 for men and 0.3 and 1 for women. We calibrate the labor supply elasticity to 0.4 .

Following Lord (1989) and Trostel (1993) we specify the intensive human capital production function to be

$$
F(e, I)=F_{0} I^{\varsigma} e^{1-\varsigma} .
$$

In order to keep the model tractable and differing from the literature, current skills do not enter human capital production, such that investment in skills has no compounding effect, cf. (22). The private cost shares of time and goods invested in education are about $75 \%$ and $25 \%$ (Becker, 1993). We therefore specify $\varsigma=0.25$

\footnotetext{
${ }^{9}$ ISCED is the International Standard Classification of Education.
} 


\subsection{Production Technology}

For general production functions with more than two inputs, there are multiple possible definitions for the elasticity of substitution between pairs of input. The one most commonly used is the Allen-Uzawa partial elasticity of substitution which measures the percentage change in the ratio of two inputs in response to a change in the ratio of the two input prices, holding all other prices - but not all other inputs - and the output quantity constant. This measure is widely used in the empirical literature, e.g. by Sato (1967), Griliches (1969), and Goldin and Katz (1998). The Allen-Uzawa elasticity of substitution is

$$
\sigma^{i, j} \equiv \frac{C^{1}(\mathbf{w}) C_{i, j}^{1}(\mathbf{w})}{C_{i}^{1}(\mathbf{w}) C_{j}^{1}(\mathbf{w})}
$$

where $C^{1}$ denotes total cost of final output and subscripts refer to partial derivatives with respect to inputs $i$ and $j .{ }^{10} \mathbf{w}$ is the vector of unit prices of the input factors in $\mathbf{q}=\left\{L^{1}, L^{2}, L^{3}, K\right\}$. Denote by $k$ the deepest aggregate containing both inputs $i$ and $j$. In the production function (25) with the nest at level 1 producing final output, the elasticities of substitution between any two input factors $i$ and $j$ write as

$$
\sigma^{i, j}=\sigma^{1}+C^{1} \sum_{n=2}^{k} \frac{\left(\sigma^{n}-\sigma^{n-1}\right)}{C^{n}}
$$

where $C^{l}$ is the total cost of a nest at level $l$ and $\sigma^{l}=\frac{1}{1-\kappa^{l}}$. Note that the elasticity of substitution between $i$ and $j$ is independent of the subnest elasticity in all nests $s>k$. Applying the concept of capital-skill complementarity implies in the setting of our production technology that

$$
\sigma^{K, L^{i}}<\sigma^{K, L^{j}} \Leftrightarrow i>j .11
$$

${ }^{10}$ Another measure is the Hicks-Allen direct partial elasticity of substitution which measures the percentage change in the ratio of two inputs in response to a change in the ratio of the two input prices, holding all other prices, inputs, and the output quantity constant. Assume a general production technology $Y=F(\mathbf{q})$. Letting $F_{i} \equiv \partial F / \partial q^{i}$, the direct partial elasiticty of substitution between the $\mathrm{i}^{\text {th }}$ and the $\mathrm{j}^{\text {th }}$ element in $\mathbf{q}$ is given by $\sigma^{d, i, j}=-\partial \ln \left(q^{i} / q^{j}\right) / \partial \ln \left(F_{i} / F_{j}\right)$, where $Y$ and all $q^{k \notin\{i, j\}}$ are held constant.

${ }^{11}$ Duffy, Papageorgiou, and Perez-Sebastian (2004) show that in the two-level CES specification of (25) with $L^{1}$ denoting high-skilled labor and $L^{2}$ low-skilled labor, the capital-skill complementarity holds iff $\sigma^{1}<\sigma^{2}$, regardless of which elasticity measure is used. We are well aware that the Allen-Uzawa elasticity as a measure of substitutability lacks the salient theoretical properties the Hicksian elasticity of substitution exhibits in the two-goods case (cf. Blackorby and Russell, 1989). Since most of the empirical literature deals with that measure, however, we also stick to it. 
The relative income shares of the three kinds of labor and capital are known from data. The elasticities of substitution between capital and skilled / unskilled labor is taken from the empirical literature. Using three types of labor, it is clear that high skilled labor is even more complementary with capital than skilled labor in the literature dealing with two kinds of labor only. Hence, we correct the respective elasticities of substitution between capital and skilled / unskilled labor accordingly. The values of $\sigma^{1}, \sigma^{2}, \sigma^{3}$ are computed from (13) recursively:

$$
\begin{aligned}
\sigma^{1} & =\sigma^{K, H^{1}}, \\
\sigma^{2} & =\frac{C^{2}}{C^{1}}\left(\sigma^{K, H^{2}}-\sigma^{1}\right)+\sigma^{1}, \\
\sigma^{3} & =\frac{C^{3}}{C^{1}}\left(\sigma^{K, H^{3}}-\sigma^{1}-\frac{C^{1}}{C^{2}}\left(\sigma^{2}-\sigma^{1}\right)\right)+\sigma^{2} .
\end{aligned}
$$

Using $\kappa_{s} \equiv 1-\frac{1}{\sigma^{s}}$ we get $\kappa_{1}=0.375, \kappa_{2}=0.045, \kappa_{3}=-0.238$ (cf. figure 12). From national accounting we know the income shares of the different production factors. Taking these into account, we can calibrate the distribution coefficients $a_{1}=0.163, a_{2}=0.365, a_{3}=0.288$.

Using a nested CES production technology with two kinds of labor, Krusell, Ohanian, Rios-Rull, and Violante (2000) estimate the elasticity of substitution between unskilled labor and capital to be 1.67. This is close to the value of 1.5 reported by Johnson (1997). Duffy, Papageorgiou, and Perez-Sebastian (2004) report a range from 1.3 to 10 for this value. Similarly, the estimate by Krusell, Ohanian, Rios-Rull, and Violante (2000) of the elasticity of substitution between skilled labor and capital is 0.67 , which is in the range of the estimations by Hamermesh (1993). The estimates by Krusell, Ohanian, Rios-Rull, and Violante (2000) are also used in Lindquist (2004). There are no estimates for three types of labor up to date. In order to account for a third skill class, we set the elasticity of substitution between capital and low, medium, and high skill labor to 1.5, 1.0, and 0.6 , respectively.

\section{Simulation Scenarios}

We start our simulations with a pure aging scenario, which consists of people becoming older on average and potentially living longer. In a second step, we 
compare the aging scenario with a scenario, where retirement is postponed accordingly by exogenous imposition, which potentially offsets the adverse economic consequences of aging. Similar scenarios have been considered by Miles (1999), Echevarría (2004), and Bovenberg and Knaap (2005).

Becoming older in our model means that the mass of people in their 80 s becomes larger because more of the younger agents make it to their 80s. Living longer means that the life-time horizon gets longer. To implement the scenario, we raise the survival rates of age groups 5 to 8 by the factors given in table 5.3 but keep the expected duration in each age group constant. The mortality rates $1-\gamma^{a}$ decline, which necessarily implies that a larger fraction of this group moves to the next one, instead of dying. Since the last group becomes less mortal, $1-\gamma^{8}$ falling from 0.2 to 0.12 , expected duration in that group rises from 5 to $\left(1-\gamma^{8}\right)^{-1}=8.3$ years. The representative agent lives longer, namely 93.3 instead of 90 years. This corresponds to the aging scenario in Kalemli-Ozcan, Ryder, and Weil (2000) who discuss the implications of longevity in a model with a single mortality rate.

Table 5.3

Aging and life-expectancy.

\begin{tabular}{lrrrrrrrr}
\hline Age groups & 1 & 2 & 3 & 4 & 5 & 6 & 7 & 8 \\
\hline Initial $N^{a}$ & 0.179 & 0.177 & 0.175 & 0.168 & 0.148 & 0.107 & 0.031 & 0.016 \\
New $N^{a}$ & 0.179 & 0.177 & 0.175 & 0.168 & 0.148 & 0.121 & 0.047 & 0.058 \\
Factor $\times \gamma^{a}$ & 1.000 & 1.000 & 1.000 & 1.000 & 1.010 & 1.020 & 1.050 & 1.100 \\
Prob. $1-\gamma^{a}$ & 0.001 & 0.001 & 0.004 & 0.012 & 0.018 & 0.023 & 0.050 & 0.120 \\
Prob. $1-\omega^{a}$ & 0.099 & 0.099 & 0.096 & 0.089 & 0.083 & 0.079 & 0.158 & 0.000 \\
\hline
\end{tabular}

In the simulations, we start with a net foreign debt-GDP ratio calibrated to equal 0.25. In a small open economy, the real interest rate is fixed on world markets. Any imbalance between domestic savings and investment is thus reflected in a change in the net foreign asset position. ${ }^{12}$

\footnotetext{
${ }^{12}$ In a closed economy, the domestic real interest rate would adjust to keep net foreign assets to zero. This second scenario would also be interesting, as aging is a worldwide phenomenon that might lead to a decline in the real interest rate via increased savings. For example, computations by Börsch-Supan, Ludwig, and Winter (2004) yield a decline in the return to capital by roughly one percentage point as a result of worldwide aging.
} 


\subsection{Population Aging}

The effects of population aging are summarized in table 5.6 in the appendix. Even though the interest rate remains constant, the ratio between capital and the three different kinds of labor varies due to the nested CES-production technology described in appendix 8.4. Aging results in a larger number of old people. In the absence of an offsetting decline in fertility, the mass of younger age groups remains unchanged, leading to a constant workforce. By assumption, the increased number of retirees increases required PAYG contributions by almost $40 \%$. These crowd out private savings and aggregate asset holdings by households (-22.5\% in the baseline case), which is reflected in a sharp decrease in net foreign assets. The projected fall in savings is also found by Miles (1999). Since PAYG contributions are lump-sum, there is no direct effect on wages and labor supply; GDP and the capital stock remain virtually unchanged. The slight increase in the capital stock induces a rise of wage differentials. The decrease in the utility differences between skill classes, which leads to a fall in educational attainment, is due to the increase in total pension benefits, which is relatively more important for unskilled labor. The resulting decrease of the high-skilled workforce increases the wage of skilled labor, which leads to an increase in individual labor supply of skilled workers. Human wealth, consisting of human capital and social security wealth, increases in all skill classes; the increase in total pension entitlements benefits low-skilled workers most, however, because the proportional increase in PAYG contributions affects them least relative to their total wealth.

\subsection{Population Aging and Postponed Retirement}

In the second simulation, we consider an increase in the retirement age by two years. The third simulation will then merge the two first scenarios in order to evaluate the combined effect of aging and pension reform. For simplicity, we impose the postponement of retirement exogenously.

A two-year postponement of retirement increases the workforce by $3.6 \%$ while reducing the number of retirees by $16.1 \%$ (cf. table 5.7 in the appendix). Keeping per-capita pension benefits constant, this results in a decrease in necessary PAYG contributions by $18.2 \%$. Postponed retirement reduces the need for individual pension savings, so that asset holdings decrease by $8.2 \%$ in the baseline case. Postponed retirement prolongs the redemption period of investments in human 
capital, such that the utility difference between skilled and unskilled workers increases and educational attainment rises. Also, education at the intensive margin rises due to a longer redemption period of human capital investments. This is reflected in increased levels of human wealth. These results are perfectly in line with the comparative static effects found in section 4.4 in the context of the illustrative model. In a similar experiment, Trostel (1993) finds that the level of the income tax rate decisively affects human capital accumulation. ${ }^{13}$ However, his quantitative results are not directly comparable to ours, since an increase in the income tax rate affects both the costs and benefits of investment in human capital, while in our setting, postponed retirement only affects the benefit side of the education decision.

The third simulation considers a scenario on top of population aging with potentially less severe economic consequences due to the postponement of retirement (cf. table 5.8 in the appendix). ${ }^{14}$ Part of the overall population increase accrues now to workers. Therefore, PAYG payments increase only by $20.2 \%$, compared to $40 \%$ in the case of constant retirement. Also, the adverse skill choice effects are somewhat mitigated. However, since postponed retirement reduces the time individuals stay in retirement, there is less need for individual savings to augment consumption possibilities at later ages. Therefore, the decrease in asset holdings due to aging is even aggravated. This effect is a result, however, of the low level of PAYG payments. Higher benefit levels would lessen the need for private savings and therefore dampen the adverse effect of postponed retirement on asset holdings. The disproportionate increase of low skilled individuals' human wealth lowers educational attainment and thereby the capital stock via the complementarity between capital and high skilled labor, as discussed in section 4. Together, they depress GDP by $2.3 \%$ in the baseline simulation. Hence, considering individual saving effects and allowing for capital-skill complementarity in production results in postponed retirement not being appropriate to mitigate adverse economic effects of population aging.

Figure 8 displays the discrete skill choice over time. The solid line depicts the choice for high skilled labor relative to the initial steady state. The dashed and dotted lines show medium and low skilled labor, respectively.Reduced utility dif-

\footnotetext{
${ }^{13}$ In his simulation, a one percent increase in the income tax rate causes human capital to decline by 0.39 percent.

${ }^{14}$ In fact, based on welfare considerations, Andersen (2005) argues that retirement age should be proportional to expected life length, just as edcuation with respect to the length of the working period in (4) and (5) in our simple illustrative model.
} 
Figure 8Discrete skill choice over time.

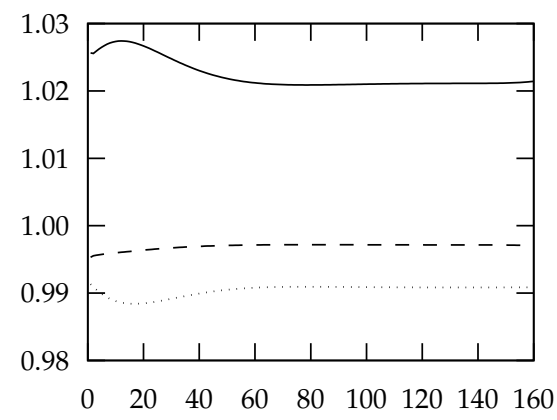

ferences between different skill classes sharply decrease educational attainment. In the long run, wages adjust, and attainment returns towards its initial level. This is exactly the effect in shown in 4 in the context of the stylized model. The relative size of the three skill groups evolves according to the inflows of individuals into these groups, as displayed in figure 9. Again, the solid line depicts high skilled labor relative to the initial steady state. The dashed and dotted lines show medium and low skilled labor, respectively.

Figure 9The size of the three skill classes.

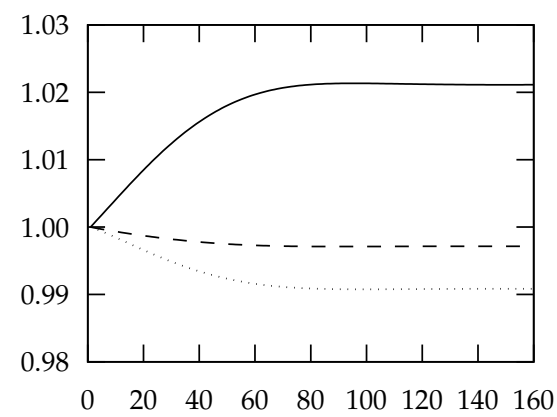

The key model parameters are the elasticity of substitution between capital and the three different kinds of labor as well as the education choice parameters at the extensive and intensive margin. We check the robustness of our results and the importance of the educational decision margins by varying the values of these parameters. Table 5.4 displays the sensitivity of the effect of aging and postponed retirement on aggregate human wealth. Overall, human wealth increases due to the prolongation of the redemption period, which yields investments in human capital more profitable at any stage of the life-cycle. 
Table 5.4

Sensitivity of human wealth to education parameters.

\begin{tabular}{rrrrrr}
\hline & $\varepsilon^{e}=0.10$ & $\varepsilon^{e}=0.30$ & $\varepsilon^{e}=0.50$ & $\varepsilon^{e}=0.70$ & $\varepsilon^{e}=0.90$ \\
\hline$\varepsilon^{d}=0.05$ & 19.813 & 26.204 & 33.766 & 42.877 & 54.123 \\
$\varepsilon^{d}=0.10$ & 19.320 & 25.644 & 33.148 & 42.216 & 53.438 \\
$\varepsilon^{d}=0.15$ & 19.028 & 25.315 & 32.787 & 41.832 & 53.043 \\
$\varepsilon^{d}=0.20$ & 18.834 & 25.098 & 32.550 & 41.580 & 52.784 \\
$\varepsilon^{d}=0.25$ & 18.695 & 24.943 & 32.381 & 41.401 & 52.601 \\
\hline
\end{tabular}

As economic intuition suggests, total human wealth reacts the more, the higher the training elasticity with respect to training returns $\varepsilon^{e}$. However, its responsiveness decreases in the semi-elasticity of the discrete skill choice decision. This this is due to the negative reaction of educational attainment to aging and postponed retirement, which partly offsets the positive effect on intensive human capital formation.

Table 5.5 shows the sensitivity of human wealth to the elasticities of substitution between capital and low-skilled labor, $\sigma^{K, L_{1}}$, and between capital and highskilled labor, $\sigma^{K, L_{3}}$, which determine the degree of complementarity between capital and skill. The larger the difference $\sigma^{K, L_{1}}-\sigma^{K, L_{3}}$, the larger is the complementarity. In the first column, all elasticities of substitution between capital and labor are equal to unity, as e.g. with a Cobb-Douglas production technology. As in table 5.4, an increase in the skill choice semi-elasticity reduces the response of human wealth to aging and postponed retirement due to lower attainment. An increase in capital-skill complementarity affects the response of human wealth to aging and postponed retirement only to the degree that individuals actually adapt their skill choice to labor market conditions, i.e. with $\varepsilon^{d}$ close to zero, capital-skill complementarity is of little economic importance.

\section{Conclusion}

In this paper, we study the importance of education and human capital formation in a macroeconomic context. We apply the concept of probabilistic aging with endogenous discrete skill choice to analyze the economic impact of aging during demographic transition. The model setting allows for an appraisal of 
Table 5.5

Sensitivity of human wealth to capital-skill complementarity.

\begin{tabular}{rrrrrr}
\hline & $\sigma^{K, L^{1}}=1.0$ & $\sigma^{K, L^{1}}=1.5$ & $\sigma^{K, L^{1}}=2.0$ & $\sigma^{K, L^{1}}=2.5$ & $\sigma^{K, L^{1}}=3.0$ \\
& $\sigma^{K, L^{3}}=1.0$ & $\sigma^{K, L^{3}}=0.8$ & $\sigma^{K, L^{3}}=0.6$ & $\sigma^{K, L^{3}}=0.4$ & $\sigma^{K, L^{3}}=0.2$ \\
\hline$\varepsilon^{d}=0.01$ & 27.063 & 27.064 & 27.064 & 27.064 & 27.064 \\
$\varepsilon^{d}=0.05$ & 26.229 & 26.204 & 26.182 & 26.163 & 26.145 \\
$\varepsilon^{d}=0.10$ & 25.705 & 25.648 & 25.594 & 25.547 & 25.500 \\
$\varepsilon^{d}=0.50$ & 24.730 & 24.571 & 24.414 & 24.265 & 24.110 \\
$\varepsilon^{d}=0.90$ & 24.543 & 24.357 & 24.171 & 23.993 & 23.805 \\
\hline \multicolumn{7}{l}{ Notes: $\sigma^{K, L^{2}}=1.0, \varepsilon^{e}=0.3}$.
\end{tabular}

inter- and intragenerational distribution effects by considering eight age groups and three skill classes with endogenous human capital accumulation at the extensive and intensive margin. The empirically well established complementarity between capital and skilled labor is embraced in a nested CES production technology. Simulating the effect of aging on key macro variables, we find that the remunerations of labor in different skill classes and accordingly their size are very differently affected. In a small open economy, where the interest rate is tied to international capital markets, GDP contracts due to decreased labor supply as a result of lower net wages and the adverse effect on educational attainment. Postponed retirement solves this problem partially by prolonging the redemption period of investments in human capital and thereby inducing higher extensive and intensive education. However, it introduces a new one: decreased private savings due to a lower need for funded old-age benefits. 


\section{Appendix}

This first appendix outlines the concept of probabilistic aging as in Grafenhofer, Jaag, Keuschnigg, and Keuschnigg (2005), which allows for the possibility that an individual keeps her individual characteristics, such as age and productivity in the next time-period, but also that she may be struck by sudden death. In the second appendix, we describe individual life-cycle optimization with respect to labor supply and intensive education. The third appendix contains a discussion of the extensive education decision. In the fourth appendix, we present the production part of the model with capital-skill complementarity in the production technology. The fifth appendix contains the simulation results in table form.

\subsection{Probabilistic Aging}

In order to reproduce realistic wage profiles, individuals must undergo some kind of aging. To preserve aggregability, aging is absent in Blanchard-style models of "perpetual youth" with overlapping generations. Since we are interested in modeling life-cycle wage-profiles in the context of an OLG model of the Blanchard style, while still being able to find closed-form aggregate solutions, we use the concept of probabilistic aging to model aging as shown in figure 10. In this section, we concentrate on individual decisions once their skill level $s$ is determined and fixed. We therefore temporarily drop superscript $s$. Each individual is a member of one of $A$ age- or productivity-groups $a \in\{1, \ldots, A\}$. Individuals are born in age group $a=1$ as workers. The affiliation of a variable at time $t$ to an individual currently belonging to age-group $a$ is denoted by $(\cdot)_{t}^{a}$.

To model demographics, we allow for mortality among all age groups. When an individual with an arbitrarily given life-cycle history plans for next period, she faces the risk of aging and dying (cf. figure 10). She must thus reckon with three possible events: (i) she dies with probability $1-\gamma^{a}$; (ii) she survives without aging and remains in the same age group with probability $\gamma^{a} \omega^{a}$, and (iii) she survives and ages and belongs to age group $a+1$ next period with probability $\gamma^{a}\left(1-\omega^{a}\right)$. Individuals in the last age group have exhausted the aging process and remain in this group with probability one, $\omega^{A}=1$. They may either survive with probability $\gamma^{A}$ within group $A$ or die with probability $1-\gamma^{A}$. In this setting, time passes faster than age, i.e. individuals normally stay in the same age-group 
for several periods. The last age group behaves according to the mortality and demographic assumptions of Blanchard's (1985) perpetual youth model.

\section{Figure 10}

Aging and mortality hazard of individuals in the model

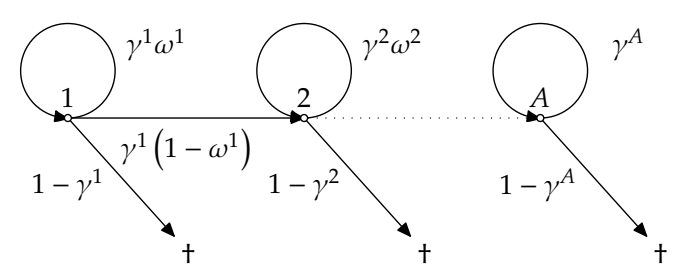

The number of agents at date $t$, in state of life $a$ and with aging history $\alpha$ is given by $N_{\alpha, t}^{a}$. Within this group, agents are identical up to their skill level and asset holdings and face the same independent probability of moving to one of the alternative states. With stochastically independent risks, the law of large numbers implies that the above stated individual probabilities correspond to the fraction of people that are subject to the respective event. Consequently, the group is divided into three subgroups next period: (i) those who die, (ii) those who survive within the same age group $a$, and (iii) those who are hit by an aging event, switch to the next higher age group. The age group and the biography $\alpha$ remains unchanged in case (ii) while switching to the next higher age group $a+1$ in case (iii) adds another event in a person's life-cycle history $\alpha$ and thereby results in a new biography $\alpha^{\prime}$ :

$$
\begin{array}{rlll}
\text { (i) } N_{\alpha^{\dagger}, t+1}^{\dagger} & =N_{\alpha, t}^{a} \cdot\left(1-\gamma^{a}\right), & \text { death, } \\
\text { (ii) } N_{\alpha, t+1}^{a}=N_{\alpha, t}^{a} \cdot \gamma^{a} \omega^{a}, & \text { no aging, } \\
\text { (iii) } N_{\alpha^{\prime}, t+1}^{a+1}=N_{\alpha, t}^{a} \cdot \gamma^{a}\left(1-\omega^{a}\right), & \text { aging. }
\end{array}
$$

Since the characteristics of people such as their earnings potential differ across age groups, an agent's consumption, assets and other economic variables will generally depend on her particular life-cycle history. For example, assets depend on the agent's past earnings history which, in turn, is linked to her aging trajectory. To keep track of the population's heterogeneity, one must thus identify each agent by her age group as well as her aging biography $\alpha$ which also includes the date of birth. An agent's life-cycle history is her biography of aging events that have happened since birth. At date $t$, the set of possible histories of a household that belongs to age group $a$ is

$$
\aleph_{t}^{a} \equiv\left\{\left(\alpha_{1}, \ldots, \alpha_{a}\right): \alpha_{1}<\ldots<\alpha_{a} \leq t\right\} .
$$


A particular life-cycle history is represented by a vector $\alpha \in \aleph_{t}^{a}$. The element $\alpha_{i}$, $i \in\{1, \ldots, a\}$, denotes the date at which the household who was formerly in age group $i-1$ became a member of group $i$. In denoting the unborn by a virtual age group zero, the element $\alpha_{1}$ lists the date of birth when an agent switches from the group of the unborn to the first age group. We say that a member of group $a=1$ aged only once with no further aging since birth. Nevertheless, different persons of the first age group are heterogeneous since they were born at different moments in the past. The set of possible biographies is then $\aleph_{t}^{1}=\left\{\left(\alpha_{1}\right): t \geq \alpha_{1}\right\}$. With this notation, the vectors $\alpha$ describing the biography of people in group $a$ have $a$ elements since such persons have aged $a$ times in total.

The individual biographies are updated when a person is subject to an aging event. Suppose a person is in age group $a-1$ and is identified by a given biography $\alpha=\left(\alpha_{1}, \ldots, \alpha_{a-1}\right)$. When the next aging event occurs in period $t$, she arrives in group $a$ next period. Her biography is appended by the entry $t+1$ and will thus read $\left(\alpha_{1}, \ldots, \alpha_{a-1}, t+1\right)$. Accordingly, the set $\aleph_{t}^{a}$ of biographies of age group $a$ will be augmented next period by all the biographies $\alpha^{\prime} \in \aleph_{t}^{a-1} \times(t+1)$ that have $t+1$ as their last entry and refer to people who currently switch from group $a-1$ to $a$. Hence,

$$
\aleph_{t+1}^{a}=\aleph_{t}^{a} \cup \aleph_{t}^{a-1} \times(t+1), \quad a \in\{1, \ldots, A\} .
$$

Result 1 With the number of individuals in age group a given by

$$
N_{t}^{a} \equiv \sum_{\alpha \in \aleph_{t}^{a}} N_{\alpha, t}^{a}
$$

(a) the aggregate law of motion for age group $1<a \leq A$ is

$$
N_{t+1}^{a}=\gamma^{a} \omega^{a} \cdot N_{t}^{a}+\gamma^{a-1}\left(1-\omega^{a-1}\right) \cdot N_{t}^{a-1}, \quad \omega^{A}=1,
$$

(b) age group 1 evolves according to

$$
N_{t+1}^{1}=\gamma^{1} \omega^{1} \cdot N_{t}^{1}+N_{(t+1), t+1}^{1}
$$

(c) total population grows by

$$
N_{t+1}=N_{t}+N_{(t+1), t+1}^{1}-\sum_{a=1}^{A}\left(1-\gamma^{a}\right) N_{t}^{a}, \quad N_{t} \equiv \sum_{a=1}^{A} N_{t}^{a} .
$$

Proof. Cf. Grafenhofer, Jaag, Keuschnigg, and Keuschnigg (2005). 


\subsection{Life-Cycle Optimization}

In different stages of the life-cycle, the individuals' choice set varies, such that intertemporal optimization differs across age-groups. As a representative case, we sketch the problem of individuals belonging to the last working age-group. The analogous problem of other age-groups is detailed in Jaag, Keuschnigg, and Keuschnigg (2005).

Individuals are working with probability $\pi_{t}$ and retired with probability $1-\pi_{t}$. Workers use time for post-school training $e$ and hours worked $l$, giving rise to effort costs $\varphi_{e}$ and $\varphi_{l}$ for education and work, respectively, multiplied by skill $\theta$. State variables are assets $A$ and skills $\theta$. Preferences are assumed additively separable in consumption $C$ and job related efforts. The per-capita Bellman equation for maximizing expected life-time utility is ${ }^{15}$

$$
\begin{aligned}
V\left(A_{\alpha, t}^{a}, \theta_{\alpha, t}^{a}\right) & =\max _{Q_{, \zeta, e, l}}\left[\left(Q_{\alpha, t}^{a}\right)^{\rho}+\gamma^{a} \beta\left(G \bar{V}_{\alpha, t+1}^{a}\right)^{\rho}\right]^{1 / \rho}, \\
Q_{\alpha, t}^{a} & =C_{\alpha, t}^{a}-\pi_{t} \varphi_{l}\left(l_{t}^{a}\right) \theta_{\alpha, t}^{a}-\pi_{t} \varphi_{e}\left(e_{t}^{a}\right) \\
\bar{V}_{\alpha, t+1}^{a} & \equiv \omega^{a} V_{\alpha, t+1}^{a}+\left(1-\omega^{a}\right) V_{\alpha^{\prime}, t+1}^{a+1} .
\end{aligned}
$$

With $R$ denoting the real interest factor and $G$ an exogenous growth rate, workers accumulate assets and skills according to

$$
\begin{aligned}
\gamma^{a} G A_{\alpha, t+1}^{a} & =R_{t+1}\left[A_{\alpha, t}^{a}+\pi_{t}\left(y_{\alpha, t}^{a}+z_{t}^{a_{W}}\right)+\left(1-\pi_{t}\right) z_{t}^{a_{R}}-Q_{\alpha, t}^{a}\right] \\
G \theta_{\alpha, t+1}^{a} & =\left(1-\delta^{S}\right) \theta_{\alpha, t}^{a}+F\left(e_{\alpha, t}^{a}, I_{\alpha, t}^{a}\right),
\end{aligned}
$$

where $z_{t}^{a_{W}}$ is an exogenous transfer or a lump-sum tax to workers, $z_{t}^{a_{R}}$ a transfer to retirees, $\delta^{S}$ skill depreciation, and $F(\cdot)$ is the intensive skill production function, assumed to be linear homogenous. Switching to the next age-group implies $\theta_{\alpha^{\prime}, t+1}^{a+1}=\theta_{\alpha, t+1}^{a}$ and $A_{\alpha^{\prime}, t+1}^{a+1}=A_{\alpha, t+1}^{a}$. Net labor income is given by

$$
y_{\alpha, t}^{a}=\left[w_{t}^{a} l_{t}^{a}-\varphi_{l}\left(l_{t}^{a}\right)\right] \theta_{\alpha, t}^{a}-\varphi_{e}\left(e_{t}^{a}\right)-I_{t},
$$

where $w_{t}^{a}$ is the wage per efficiency or productivity unit per hour, $\theta_{\alpha, t}^{a}$ is the agent's productivity (skill) resulting from past training, and $I_{\alpha, t}^{a}$ is physical investment in training (books, computers, teachers). We assume that this is a government provided rival good, and thus exogenously controlled. It is supplied

\footnotetext{
${ }^{15}$ Preferences are represented by a CES utility function as in Farmer (1990) and Weil (1990). This formulation allows for risk neutrality while the elasticity of intertemporal substitution can be chosen arbitrarily.
} 
at the same amount for all per capita, $I_{\alpha, t}^{a}=I_{t}$, and the cost of it is charged to private agents, giving rise to private spending $I_{t}$.

It is convenient to define the shadow prices $\eta_{\alpha, t}^{a}$ of assets and $\chi_{\alpha, t}^{a}$ of skills,

$$
\begin{gathered}
\eta_{\alpha, t}^{a} \equiv \frac{\partial V_{\alpha, t}^{a}}{\partial A_{\alpha, t}^{a}}\left(G V_{\alpha, t}^{a}\right)^{\rho-1}, \quad \chi_{\alpha, t}^{a} \equiv \frac{\partial V_{\alpha, t}^{a}}{\partial \theta_{\alpha, t}^{a}}\left(G V_{\alpha, t}^{a}\right)^{\rho-1}, \quad \mu_{\alpha, t}^{a} \equiv \frac{\chi_{\alpha, t}^{a}}{\eta_{\alpha, t}^{a}} \\
\bar{\chi}_{\alpha, t+1}^{a} \equiv\left[\omega^{a} \frac{\partial V_{\alpha, t+1}^{a}}{\partial \theta_{\alpha, t+1}^{a}}+\left(1-\omega^{a}\right) \frac{\partial V_{\alpha^{\prime}, t+1}^{a+1}}{\partial \theta_{\alpha^{\prime}, t+1}^{a+1}}\right]\left(G \bar{V}_{\alpha, t+1}^{a}\right)^{\rho-1}, \\
\bar{\eta}_{\alpha, t+1}^{a} \equiv\left[\omega^{a} \frac{\partial V_{\alpha, t+1}^{a}}{\partial A_{\alpha, t+1}^{a}}+\left(1-\omega^{a}\right) \frac{\partial V_{\alpha^{\prime}, t+1}^{a+1}}{\partial A_{\alpha^{\prime}, t+1}^{a+1}}\right]\left(G \bar{V}_{\alpha, t+1}^{a}\right)^{\rho-1}, \\
\bar{\mu}_{\alpha, t}^{a} \equiv \omega^{a} \mu_{\alpha, t+1}^{a}+\left(1-\omega^{a}\right)\left(\Delta_{t+1}^{a+1} / \Delta_{t+1}^{a}\right)^{\frac{1-\rho}{\rho}} \mu_{\alpha, t+1}^{a+1} .
\end{gathered}
$$

The optimality conditions for (20) subject to (21)/(22) are

$$
\begin{array}{ll}
Q_{\alpha, t}^{a}: & \left(Q_{\alpha, t}^{a}\right)^{\rho-1}=\beta R_{t+1} \bar{\eta}_{\alpha, t+1}^{a}, \\
l_{t}^{a}: & \varphi_{l}^{\prime}\left(l_{t}^{a}\right)=w_{t}^{a}, \\
e_{t}^{a}: & \varphi_{e}^{\prime}\left(e_{t}^{a}\right)=F_{E} \frac{\gamma^{a} \bar{\chi}_{\alpha, t+1}^{a}}{R_{t+1} \bar{\eta}_{\alpha, t+1}^{a}},
\end{array}
$$

where $F_{E}$ denotes the partial derivatives of $F$ with respect to $e$. The envelope theorem yields:

$$
\begin{aligned}
A_{\alpha, t}^{a}: & \eta_{\alpha, t}^{a}=G^{\rho-1} \beta R_{t+1} \bar{\eta}_{\alpha, t+1}^{a} \\
\theta_{\alpha, t}^{a}: & \mu_{\alpha, t}^{a}=w_{t}^{a} l_{t}^{a}-\varphi_{L, t}^{a}+\left(1-\delta^{S}\right) \frac{\gamma^{a} \bar{\chi}_{\alpha, t+1}^{a}}{R_{t+1} \bar{\eta}_{\alpha, t+1}^{a}} .
\end{aligned}
$$

Result 2 Consumption $Q_{\alpha, t}^{a}$ and indirect utility $V_{\alpha, t}^{a}$ are
(a) $Q_{\alpha, t}^{a}=\left(1 / \Delta_{t}^{a}\right)\left(A_{\alpha, t}^{a}+H_{\alpha, t}^{a}+S_{\alpha, t}^{a}\right), \quad \sigma=1 /(1-\rho)$,
(b) $V_{\alpha, t}^{a}=\left(\Delta_{t}^{a}\right)^{1 / \rho} Q_{\alpha, t^{\prime}}^{a}$
(c) $\Delta_{t}^{a}=1+\gamma^{a} \beta^{\sigma}\left(\Omega_{t+1}^{a} R_{t+1}\right)^{\sigma-1} \Delta_{t+1}^{a}$
(d) $\Omega_{t+1}^{a}=\omega^{a}+\left(1-\omega^{a}\right)\left(\Delta_{t+1}^{a+1} / \Delta_{t+1}^{a}\right)^{\frac{1-\rho}{\rho}}$,
(e) $H_{\alpha, t}^{a}=\pi_{t} y_{\alpha, t}^{a}+\gamma^{a} G \bar{H}_{\alpha, t+1}^{a} /\left(\Omega_{t+1}^{a} R_{t+1}\right)$,
$y_{\alpha, t}^{a}=\left[w_{t}^{a} l_{t}^{a}-\varphi_{l}\left(l_{t}^{a}\right)\right] \theta_{\alpha, t}^{a}-\varphi_{e}\left(e_{t}^{a}\right)-I_{t}$,
(f) $\bar{H}_{\alpha, t+1}^{a}=\omega^{a} H_{\alpha, t+1}^{a}+\left(1-\omega^{a}\right)\left(\Delta_{t+1}^{a+1} / \Delta_{t+1}^{a}\right)^{\frac{1-\rho}{\rho}} H_{\alpha^{\prime}, t+1}^{a+1}$
(g) $S_{\alpha, t}^{a}=z_{t}^{a}+\gamma^{a} G \bar{S}_{\alpha, t+1}^{a} /\left(\Omega_{t+1}^{a} R_{t+1}\right)$,
(h) $\bar{S}_{\alpha, t+1}^{a}=\omega^{a} S_{\alpha, t+1}^{a}+\left(1-\omega^{a}\right)\left(\Delta_{t+1}^{a+1} / \Delta_{t+1}^{a}\right)^{\frac{1-\rho}{\rho}} S_{\alpha^{\prime}, t+1}^{a+1}$. 
$\Omega_{t+1}^{a}$ augments the interest rate $R_{t+1}$, accounting for the expected finiteness of life, $\Delta_{t}^{a}$ is the inverse of the marginal propensity to consume, $H$ is human capital, and $S$ is social security wealth.

Proof. Cf. Jaag, Keuschnigg, and Keuschnigg (2005), proposition 3.

Physical investment in education $I$ being determined exogenously, there are private rents on education $y^{a}{ }^{a}$, which derive from the inframargial effort and the non-optimal supply of $I$.

Result 3 Human capital can be written as shadow price times accumulated skills:

$$
H_{\alpha, t}^{a}=\mu_{t}^{a} \theta_{\alpha, t}^{a}+h r_{t}^{a}, \quad h r_{t}^{a}=y r_{t}^{a}+\frac{\gamma^{a} G \overline{h r}_{t+1}^{a}}{R_{t+1} \Omega_{t+1}^{a}},
$$

where

$$
\begin{aligned}
y r_{t}^{a} & =F_{t}^{a} \frac{\gamma^{a} \bar{\mu}_{t+1}^{a}}{R_{t+1} \Omega_{t+1}^{a}}-\pi_{t} \varphi_{E}^{a}-\delta_{t} I, \\
\bar{h} r_{t+1}^{a} & =\omega^{a} h r_{t+1}^{a}+\left(1-\omega^{a}\right)\left(\Delta_{t+1}^{a+1} / \Delta_{t+1}^{a}\right)^{\frac{1-\rho}{\rho}} h r_{t+1}^{a+1} .
\end{aligned}
$$

Proof. Cf. Jaag, Keuschnigg, and Keuschnigg (2005), equation (28).

\subsection{Discrete Skill Choice}

At the beginning of their life-cycle individuals choose their skill level. For simplicity, we assume this education to be instantaneous with no time being consumed. ${ }^{16}$ We distinguish several discrete skill classes and introduce an upper index $s \in\{1, \ldots S\}$ to identify these groups (e.g. high, medium and low skilled in case of three groups). The structure of individual decisions in the preceding section is identical for all skill classes. Indirect utility of a new agent born at date $t$ with skill $s$ is $V_{(t), t}^{s, 1}$. This agent necessarily belongs to age group 1 and has history $\alpha_{1}=t$. Let $\varphi_{v}^{s}>0$ be the incremental education effort cost that an agent with skill $s$ needs to spend to obtain skill $s+1$. The discrete skill choice at the beginning of the life-cycle is

$$
s=\arg \max _{\tilde{s} \in\{1, \ldots, S\}} V_{(t), t}^{\tilde{s}, 1}-\sum_{i=1}^{\tilde{s}-1} \varphi_{v}^{i}(v), \quad \frac{d \varphi_{v}^{i}(v)}{d v}>0 .
$$

\footnotetext{
${ }^{16}$ Mincer (1991) argues that - opposed to investment in on-the-job-training - almost none of the goods invested in education are bought with foregone earnings.
} 
To obtain a determinate education decision, we must assume heterogeneity of agents with respect to ability, which is inversely related to the index $v \in[0, \bar{v}]$.

The discrete skill choice is most easily found by starting with the lowest skill class $s=1$ and asking whether it pays to obtain the next higher degree. Following this procedure, an agent with skill $s$ acquires the incremental education to obtain degree $s+1$ if the following inequality derived from (23) holds: $V_{(t), t}^{s+1,1}>V_{(t), t}^{s, 1}+\varphi_{v}^{s}(v)$. For high cost, low ability persons, it is eventually not worthwhile anymore to incur the incremental education cost. Hence, there exists a critical agent $v^{s}$ who is just indifferent between degrees $s$ and $s+1$ :

$$
V_{(t), t}^{s+1,1}=V_{(t), t}^{s, 1}+\varphi_{v}^{s}(v) \Rightarrow v_{t}^{s} .
$$

Since education cost increases in $v$, agents with lower ability $v>v^{\mathcal{s}}$ and higher cost remain with skill s. Figure 11 illustrates.

\section{Figure 11}

Discrete skill choice with three skill classes.

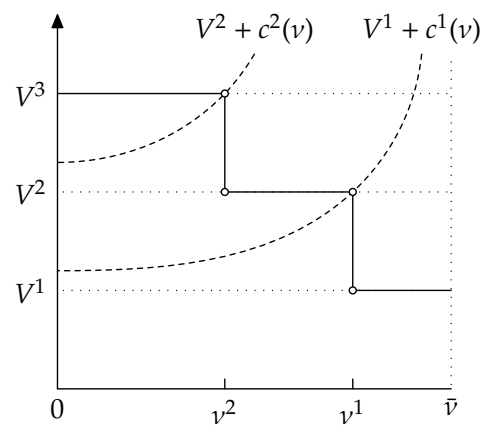

New agents are distributed by the cumulative distribution function $\Gamma(v)$. Of all $N_{(t), t}^{1}$ new agents in period $t$, a share $p_{t}^{s}$ chooses skill group $s$ where 1 gives the lowest and $S$ the highest skill group:

$$
N_{(t), t}^{s, 1}=N_{(t), t}^{1} t_{t}^{s}, \quad p_{t}^{s}= \begin{cases}1-\Gamma\left(v_{t}^{1}\right) & s=1, \\ \Gamma\left(v_{t}^{s-1}\right)-\Gamma\left(v_{t}^{s}\right) & 1<s<S, \\ \Gamma\left(v_{t}^{S}\right) & s=S .\end{cases}
$$

The educational choice is open only to new households while older ones are locked into their previously chosen skill group. Hence, the law of motion for the number of individuals in age-group 1 with skill level $s$ is

$$
N_{t+1}^{s, 1}=\gamma^{1} \omega^{1} N_{t}^{s, 1}+N_{(t+1), t+1}^{s, 1} .
$$


Assume a uniform distribution of the population $v \sim U(0,1)$ implies $\Gamma\left(v^{s}\right)=v^{s}$. We specify the cost of education to be

$$
c^{s}(v)=\xi^{s} \exp \left(v^{s} / \varepsilon_{d}\right) \Rightarrow v_{t}^{s}=\varepsilon_{d}\left[\ln \Delta V_{(t), t}^{s, 1}-\ln \xi^{s}\right] .
$$

This specification implies a semi-elasticity $\varepsilon_{d}$ of the education decision with respect to $\Delta V^{s} \equiv V^{s+1}-V^{s}$, i.e. $d v^{s}=\varepsilon_{d} \cdot\left(d \Delta V^{s, 1} / \Delta V^{s, 1}\right)$. When life-time utility of skill $s+1$ increases relative to $s$, the critical value $v^{s}$ increases and the share of skill group $s$ in the new cohort declines by $d v^{s}$.

\subsection{Capital-Skill-Complementarity in Production}

In our model, we allow for differentiated labor in the production function. As opposed to Heckman, Lochner, and Taber (1998), Blundell and Bond (2000) and Blundell, Dias, and Meghir (2003), we explicitly allow for capital-skill complementarity and hence for a non-constant share of capital in production. There are several ways of nesting the differentiated production factors within a CES function, of which six allow for full capital-skill complementarity. With a monotonous ordering of labor inputs according to their skill level, there are two nestings:

$$
\begin{aligned}
Y & =\mathrm{Y}_{1}\left(L^{1}, \mathrm{Y}_{2}\left(L^{2}, \mathrm{Y}_{3}\left(L^{3}, K\right)\right)\right), \\
Y^{\prime} & =\mathrm{Y}_{1}\left(L^{3}, \mathrm{Y}_{2}\left(L^{2}, \mathrm{Y}_{3}\left(L^{1}, K\right)\right)\right),
\end{aligned}
$$

where $Y_{1}, Y_{2}, Y_{3}$ are CES aggregators. $Y^{\prime}$ implies the elasticity of substitution between $L^{3}$ and $K$ to be the same as between $L^{1}$ and $L^{3}$ by the symmetry restrictions of the CES functional form. This is at odds with factor elasticity estimates, which suggest that the substitution elasticity between skilled labor and unskilled labor is higher than the substitution elasticity between skilled labor and capital (cf. Hamermesh, 1993, and Krusell, Ohanian, Rios-Rull, and Violante, 2000). Hence, we choose $Y$ which does not seem to be at variance with elasticity estimates. This ordering of the CES nesting also conforms with the functional form chosen by Duffy, Papageorgiou, and Perez-Sebastian (2004).

For the simulations, we use a production function with three kinds of labor and 
capital as inputs of the form (cf. figure 12)

$$
\begin{aligned}
Y & =Y_{1}\left(L^{1}, Y_{2}\left(L^{2}, Y_{3}\left(L^{3}, K\right)\right)\right) \\
& =Y^{0}\left[a^{1}\left(L^{1}\right)^{\kappa^{1}}+\left(1-a^{1}\right)\left[a^{2}\left(L^{2}\right)^{\kappa^{2}}+\left(1-a^{2}\right)\left[a^{3}\left(L^{3}\right)^{\kappa^{3}}+\left(1-a^{3}\right)(K)^{\kappa^{3}}\right]^{\frac{\kappa^{2}}{\kappa^{3}}}\right]^{\frac{\kappa^{1}}{\kappa^{2}}}\right]^{\frac{1}{\kappa^{1}}} .
\end{aligned}
$$

The most aggregate nest is final output $Y$ which consists of unskilled labor $L^{1}$ and a quantity $Y^{2}$ which is the output of the next subnest and itself consists of medium skilled labor $L^{2}$ and a composite $Y^{3}$. This last quantity is a composite of high skilled labor $L^{3}$ and capital $K$. The parameters $\kappa^{1}, \kappa^{2}, \kappa^{3}$ are related to substitution elasticities and $a^{1}, a^{2}, a^{3}$ are distribution parameters. The technology is thus

$$
\begin{aligned}
Y & =Y^{0}\left[a^{1}\left(L^{1}\right)^{\kappa^{1}}+\left(1-a^{1}\right)\left(Y^{2}\right)^{\kappa^{1}}\right]^{1 / \kappa^{1}}, \\
Y^{2} & =\left[a^{2}\left(L^{2}\right)^{\kappa^{2}}+\left(1-a^{2}\right)\left(Y^{3}\right)^{\kappa^{2}}\right]^{1 / \kappa^{2}}, \\
Y^{3} & =\left[a^{3}\left(L^{3}\right)^{\kappa^{3}}+\left(1-a^{3}\right)(K)^{\kappa^{3}}\right]^{1 / \kappa^{3}} .
\end{aligned}
$$

\section{Figure 12}

Production technology with three-level nested CES structure.

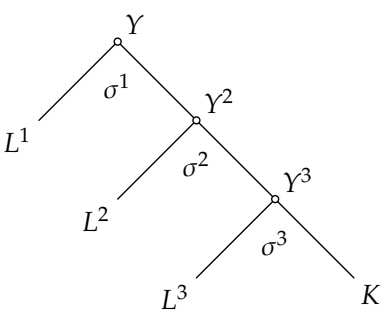

Note that only one type of labor enters at each level of nesting. The technology can be characterized by the price elasticity of demand for the input factors. Let $w^{s}$ be the unit price of labor of type $s$ and $c^{s}$ the unit cost of output of level s, i.e. $c^{s}=F_{L^{s}} \cdot L^{s} / Y^{s}+c^{s+1} \cdot Y^{s+1} / Y^{s}$. The cost minimization problem at each level $s$ is

$c^{\mathcal{s}}=\min _{L^{s}, Y^{s+1}} F_{L^{s}} \frac{L^{s}}{Y^{s}}+c^{s+1} \frac{Y^{s+1}}{Y^{s}}, \quad$ s.t. $\quad 1=\left[a^{\mathcal{s}}\left(\frac{L^{s}}{Y^{s}}\right)^{\kappa^{s}}+\left(1-a^{s}\right)\left(\frac{Y^{s+1}}{Y^{s}}\right)^{\kappa^{s}}\right]^{1 / \kappa^{s}}$. 
We get input demands at level $s$,

$$
L^{\mathcal{S}}=\left(a^{\mathcal{S}} \frac{c^{\mathcal{S}}}{F_{L^{s}}}\right)^{\sigma^{\mathcal{S}}} Y^{\mathcal{S}}, \quad Y^{\mathcal{S}+1}=\left(\left(1-a^{\mathcal{S}}\right) \frac{c^{\mathcal{S}}}{c^{\mathcal{S}+1}}\right)^{\sigma^{\mathcal{S}}} Y^{\mathcal{S}}, \quad \sigma^{\mathcal{S}} \equiv \frac{1}{1-\kappa^{\mathcal{S}}} .
$$

By forward substitution, total compensated demand for labor on aggregation level $s \in\{1,2,3\}, L^{s}$, is given by

$L^{s}=Y^{s}\left(a^{s}\right)^{\sigma^{s}}\left(\frac{c^{s}}{F_{L^{s}}}\right)^{\sigma^{s}}=Y_{t}\left(F_{L^{s}}\right)^{-\sigma^{s}}\left(a^{s}\right)^{\sigma^{s}}\left(c^{1}\right)^{\sigma^{1}} \prod_{n=2}^{s}\left(1-a^{n-1}\right)^{\sigma^{n-1}}\left(c^{n}\right)^{\sigma^{n}-\sigma^{n-1}}$.

By Shephard's lemma, the derivative of total cost with respect to $w^{i}$ equals the demand for input factor $i$ :

$$
\frac{\partial c^{s}}{\partial F_{L^{i}}}= \begin{cases}0 & i<s \\ \frac{L^{i}}{Y^{s}} & i \geq s\end{cases}
$$

Therefore, the compensated own-price elasticity of demand for labor $s$ is

$$
\frac{\partial L^{s}}{\partial F_{L^{s}}} \frac{F_{L^{s}}}{L^{s}}=-\sigma^{s}+\sigma^{1} \frac{\partial c^{1}}{\partial F_{L^{s}}} \frac{F_{L^{s}}}{c^{1}}+\sum_{n=2}^{s}\left(\sigma^{n}-\sigma^{n-1}\right) \frac{\partial c^{n}}{\partial F_{L^{s}}} \frac{F_{L^{s}}}{c^{n}} .
$$

Let $k \in\{i, j\}$ denote the deepest price aggregate which contains both $F_{L^{i}}$ and $F_{L^{j}}$. Taking into account the impact of $F_{L^{i}}$ on $c^{j \leq k}$, the cross price-elasticity is given by

$$
\varepsilon^{i, j} \equiv \frac{\partial L^{i}}{\partial F_{L^{j}}} \frac{F_{L^{j}}}{L^{i}}=\sigma^{1} \frac{\partial c^{1}}{\partial F_{L^{j}}} \frac{F_{L^{j}}}{c^{1}}+\sum_{n=2}^{k}\left(\sigma^{n}-\sigma^{n-1}\right) \frac{\partial c^{n}}{\partial F_{L^{j}}} \frac{F_{L^{s}}}{c^{n}} .
$$

In analogy, the cross price-elasticity between labor $L^{s}$ and capital $K$ is

$$
\varepsilon^{L^{s}, K} \equiv \frac{\partial L^{s}}{\partial w^{K}} \frac{w^{K}}{L^{s}}=\sigma^{1} \frac{\partial c^{1}}{\partial w^{K}} \frac{w^{K}}{c^{1}}+\sum_{n=2}^{s}\left(\sigma^{n}-\sigma^{n-1}\right) \frac{\partial c^{n}}{\partial w^{K}} \frac{w^{K}}{c^{n}},
$$

where $w^{K}$ is the cost per unit of capital.

The key parameters to consider in the calibration of the production side of the model are the elasticities of substitution between input factors. For production functions with more than two inputs, there are multiple possible definitions for the elasticity of substitution between pairs of input. The most commonly used is the Allen-Uzawa partial elasticity of substitution which measures the percentage change in the ratio of two inputs in response to a change in the ratio of the two input prices, holding all other prices - but not all other inputs - and the output 
quantity constant. This measure is widely used in the empirical literature, e.g. by Sato (1967), Griliches (1969), and Goldin and Katz (1998). The Allen-Uzawa elasticity of substitution is

$$
\sigma^{i, j} \equiv \varepsilon^{i, j} \frac{c^{1} Y^{1}}{F_{L^{j}}{ }^{j}}
$$

where $q^{j}$ is the quantity of input good $j .{ }^{17}$ Denote by $k$ the deepest aggregate containing both inputs $i$ and $j$. In the production function with the nest at level 1 producing final output, the elasticities of substitution between any two input factors $i$ and $j$ write as

$$
\sigma^{i, j}=\sigma^{1}+Y^{1} c^{1} \sum_{n=2}^{k} \frac{\left(\sigma^{n}-\sigma^{n-1}\right)}{Y^{n} c^{n}},
$$

where $c^{n}$ is the unit cost of a nest at level $n$ and $\sigma^{n}=\frac{1}{1-\kappa^{n}}$. Note that the elasticity of substitution between $i$ and $j$ is independent of the subnest elasticity in all nests $s>k$. Applying the concept of capital-skill complementarity implies in the setting of our production technology that ${ }^{18}$

$$
\sigma^{K, L^{i}}<\sigma^{K, L^{j}} \Leftrightarrow i>j .
$$

The relative income shares of the three kinds of labor and capital are known from data. The elasticities of substitution between capital and skilled / unskilled labor are taken from the empirical literature. Using three types of labor, it is clear that high skilled labor is even more complementary with capital than skilled labor in the literature dealing with two kinds of labor only. Hence, we correct the respective elasticities of substitution between capital and skilled / unskilled

\footnotetext{
${ }^{17}$ Another measure is the Hicks-Allen direct partial elasticity of substitution which measures the percentage change in the ratio of two inputs in response to a change in the ratio of the two input prices, holding all other prices, inputs, and the output quantity constant. Assume a general production technology $Y=F(\mathbf{q})$. Letting $F_{i} \equiv \partial F / \partial q^{i}$, the direct partial elasiticty of substitution between the $\mathrm{i}^{\text {th }}$ and the $\mathrm{j}^{\text {th }}$ element in $\mathbf{q}$ is given by $\sigma^{d, i, j}=-\partial \ln \left(q^{i} / q^{j}\right) / \partial \ln \left(F_{i} / F_{j}\right)$, where $Y$ and all $q^{k \notin\{i, j\}}$ are held constant.

${ }^{18}$ Duffy et al. (2004) show that in the two-level CES specification of (25) with $L^{1}$ denoting low-skilled labor and $L^{2}$ high-skilled labor, the capital-skill complementarity holds iff $\sigma^{2}<\sigma^{1}$, regardless of which elasticity measure is used. We are well aware that the Allen-Uzawa elasticity as a measure of substitutability lacks the salient theoretical properties the Hicksian elasticity of substitution exhibits in the two-goods case (cf. Blackorby and Russell, 1989). Since most of the empirical literature deals with that measure, however, we also stick to it.
} 
labor accordingly. The values of $\sigma^{1}, \sigma^{2}, \sigma^{3}$ are computed from (26) recursively:

$$
\begin{aligned}
& \sigma^{1}=\sigma^{K, H^{1}}, \quad \sigma^{2}=\frac{c^{2} Y^{2}}{c^{1} Y^{1}}\left(\sigma^{K, H^{2}}-\sigma^{1}\right)+\sigma^{1}, \\
& \sigma^{3}=\frac{c^{3} Y^{3}}{c^{1} Y^{1}}\left(\sigma^{K, H^{3}}-\sigma^{1}-\frac{c^{1} Y^{1}}{c^{2} Y^{2}}\left(\sigma^{2}-\sigma^{1}\right)\right)+\sigma^{2} .
\end{aligned}
$$




\subsection{Simulation Results}

Table 5.6

Long-run impact of aging on key macro variables

in percentage changes relative to initial steady state.

\begin{tabular}{|c|c|c|c|c|}
\hline \multicolumn{2}{|c|}{ Key macro variable } & $\sigma=0.3$ & $\sigma=0.5$ & $\sigma=0.7$ \\
\hline$r$ & Real interest rate* & 0.050 & 0.050 & 0.050 \\
\hline$D^{f} / Y$ & Debt - GDP ratio* & -0.219 & -0.360 & -0.596 \\
\hline$z^{S}$ & PAYG contributions & 39.394 & 39.394 & 39.394 \\
\hline$w^{1}$ & Wage-rate low skilled labor & -0.719 & -0.967 & -1.725 \\
\hline$w^{2}$ & Wage-rate medium skilled labor & -0.113 & -0.150 & -0.257 \\
\hline$w^{3}$ & Wage-rate high skilled labor & 0.378 & 0.506 & 0.895 \\
\hline$l^{1}$ & Low skilled labor supply & -0.288 & -0.388 & -0.694 \\
\hline$l^{2}$ & Medium skilled labor supply & -0.045 & -0.060 & -0.103 \\
\hline$l^{3}$ & High skilled labor supply & 0.151 & 0.202 & 0.357 \\
\hline$W_{(t), t}^{1,1}$ & Low skilled human wealth p.c. & 1.436 & 6.660 & 18.851 \\
\hline$W_{(t), t}^{2,1}$ & Medium skilled human wealth p.c. & 1.125 & 4.595 & 13.585 \\
\hline$W_{(t), t}^{3,1}$ & High skilled human wealth p.c. & 1.058 & 3.914 & 12.036 \\
\hline$\Delta V^{1}$ & Utility difference 1 & -5.431 & -7.295 & -12.851 \\
\hline$\Delta V^{2}$ & Utility difference 2 & -5.294 & -7.049 & -12.116 \\
\hline$N^{1}$ & Low skilled individuals & 2.939 & 3.987 & 7.240 \\
\hline$N^{2}$ & Medium skilled individuals & -0.027 & -0.049 & -0.156 \\
\hline$N^{3}$ & High skilled individuals & -2.015 & -2.707 & -4.784 \\
\hline$N^{W}$ & Number of workers & 0.000 & 0.000 & 0.000 \\
\hline$N^{R}$ & Number of retirees & 39.394 & 39.394 & 39.394 \\
\hline K & Capital stock & -0.003 & 0.106 & 0.397 \\
\hline Y & Gross domestic product, GDP & 0.068 & 0.201 & 0.568 \\
\hline C & Aggregate consumption & -2.343 & -2.928 & -3.758 \\
\hline$A$ & Aggregate assets & -17.382 & -22.510 & -31.096 \\
\hline
\end{tabular}


Table 5.7

Long-run impact of a two-year retirement postponement on key macro variables in percentage changes relative to initial steady state.

\begin{tabular}{|c|c|c|c|c|}
\hline \multicolumn{2}{|c|}{ Key macro variable } & \multirow{2}{*}{$\begin{array}{r}\sigma=0.3 \\
0.050\end{array}$} & \multirow{2}{*}{$\begin{array}{r}\sigma=0.5 \\
0.050\end{array}$} & \multirow{2}{*}{$\begin{array}{r}\sigma=0.7 \\
0.050\end{array}$} \\
\hline$r$ & Real interest rate & & & \\
\hline$D^{f} / Y$ & Debt - GDP ratio* & 0.103 & 0.090 & 0.071 \\
\hline$\overline{z^{S}}$ & PAYG contributions & -18.196 & -18.196 & -18.196 \\
\hline$w^{1}$ & Wage-rate low skilled labor & 0.231 & 0.245 & 0.275 \\
\hline$w^{2}$ & Wage-rate medium skilled labor & -0.077 & -0.072 & -0.062 \\
\hline$w^{3}$ & Wage-rate high skilled labor & 0.028 & 0.018 & -0.006 \\
\hline$l^{1}$ & Low skilled labor supply & 0.092 & 0.098 & 0.110 \\
\hline$l^{2}$ & Medium skilled labor supply & -0.031 & -0.029 & -0.025 \\
\hline$l^{3}$ & High skilled labor supply & 0.011 & 0.007 & -0.002 \\
\hline$W_{(t), t}^{1,1}$ & Low skilled human wealth p.c. & 0.982 & 1.526 & 2.786 \\
\hline$W_{(t), t}^{2,1}$ & Medium skilled human wealth p.c. & 0.742 & 1.059 & 1.769 \\
\hline$W_{(t), t}^{3,1}$ & High skilled human wealth p.c. & 0.974 & 1.217 & 1.763 \\
\hline$\Delta V^{1}$ & Utility difference 1 & 0.489 & 0.578 & 0.765 \\
\hline$\Delta V^{2}$ & Utility difference 2 & 1.371 & 1.491 & 1.751 \\
\hline$N^{1}$ & Low skilled individuals & -0.257 & -0.303 & -0.401 \\
\hline$N^{2}$ & Medium skilled individuals & -0.162 & -0.167 & -0.180 \\
\hline$N^{3}$ & High skilled individuals & 0.504 & 0.548 & 0.643 \\
\hline$N^{W}$ & Number of workers & 3.622 & 3.622 & 3.622 \\
\hline$N^{R}$ & Number of retirees & -16.131 & -16.131 & -16.131 \\
\hline K & Capital stock & -2.545 & -2.454 & -2.245 \\
\hline Y & Gross domestic product, GDP & -2.553 & -2.464 & -2.258 \\
\hline C & Aggregate consumption & -3.685 & -3.659 & -3.542 \\
\hline A & Aggregate assets & -7.837 & -8.239 & -8.741 \\
\hline
\end{tabular}

\section{References}

Acemoglu, D. (1998): “Why Do New Technologies Complement Skills? Directed Technical Change And Wage Inequality," Quarterly Journal of Economics, 113(4), 1055-1089.

Altig, D., A. J. Auerbach, L. J. Kotlikoff, K. A. Smetters, and J. WalLISER (2001): "Simulating Fundamental Tax Reform in the United States," American Economic Review, 91(3), 574-595. 
Table 5.8

Long-run impact of aging and postponed retirement on key

macro variables in percentage changes relative to initial steady state.

\begin{tabular}{|c|c|c|c|c|}
\hline \multicolumn{2}{|c|}{ Key macro variable } & $\sigma=0.3$ & $\sigma=0.5$ & $\sigma=0.7$ \\
\hline $\bar{r}$ & Real interest rate* & 0.050 & 0.050 & 0.050 \\
\hline$D^{f} / Y$ & Debt-GDP ratio* & -0.435 & -0.593 & -0.859 \\
\hline$z^{S}$ & PAYG contributions & 20.228 & 20.228 & 20.228 \\
\hline$w^{1}$ & Wage-rate low skilled labor & -0.498 & -0.740 & -1.486 \\
\hline$w^{2}$ & Wage-rate medium skilled labor & -0.191 & -0.224 & -0.324 \\
\hline$w^{3}$ & Wage-rate high skilled labor & 0.410 & 0.532 & 0.907 \\
\hline$l^{1}$ & Low skilled labor supply & -0.200 & -0.297 & -0.597 \\
\hline$l^{2}$ & Medium skilled labor supply & -0.076 & -0.090 & -0.130 \\
\hline$l^{3}$ & High skilled labor supply & 0.164 & 0.212 & 0.362 \\
\hline$W_{(t), t}^{1,1}$ & Low skilled human wealth p.c. & 2.551 & 8.219 & 21.479 \\
\hline$W_{(t), t}^{2,1}$ & Medium skilled human wealth p.c. & 1.913 & 5.628 & 15.196 \\
\hline$W_{(t), t}^{3,1}$ & High skilled human wealth p.c. & 2.046 & 5.091 & 13.664 \\
\hline$\Delta V^{1}$ & Utility difference 1 & -5.015 & -6.850 & -12.364 \\
\hline$\Delta V^{2}$ & Utility difference 2 & -4.045 & -5.758 & -10.782 \\
\hline$N^{1}$ & Low skilled individuals & 2.708 & 3.735 & 6.946 \\
\hline$N^{2}$ & Medium skilled individuals & -0.188 & -0.216 & -0.331 \\
\hline$N^{3}$ & High skilled individuals & -1.529 & -2.197 & -4.225 \\
\hline$N^{W}$ & Number of workers & 3.622 & 3.622 & 3.622 \\
\hline$N^{R}$ & Number of retirees & 23.263 & 23.263 & 23.263 \\
\hline K & Capital stock & -2.606 & -2.432 & -1.980 \\
\hline Y & Gross domestic product, GDP & -2.544 & -2.346 & -1.823 \\
\hline C & Aggregate consumption & -6.379 & -6.970 & -7.767 \\
\hline A & Aggregate assets & -27.333 & -32.918 & -42.281 \\
\hline
\end{tabular}

ANDERSEN, T. M. (2005): “Social Security and Longevity," CESifo Working Paper 1577.

Auerbach, A. J., And L. J. Kotlikoff (1987): Dynamic Fiscal Policy. Cambridge University Press, Cambridge, MA.

BARRO, R. J. (1991): “Economic Growth in a Cross Section of Countries," Quarterly Journal of Economics, 106(2), 407-443.

BECKer, G. S. (1962): “Investment in Human Capital: A Theoretical Analysis," Journal of Political Economy, 70(5), 9-49. 
(1993): Human Capital: A Theoretical and Empirical Analysis, with Special Reference to Education. University of Chicago Press, Chicago, 3rd edn.

Ben-Porath, Y. (1967): "The Production of Human Capital and the Life Cycle of Earnings," Journal of Political Economy, 75(4), 352-365.

BFS (2001): Szenarien zur Bevölkerungsentwicklung der Schweiz 2000-2060. Bundesamt für Statistik, Neuchâtel.

(2004): Die Schweizerische Arbeitskräfteerhebung (SAKE). Bundesamt für Statistik, Neuchâtel.

Bils, M., And P. J. Klenow (2000): “Does Schooling Cause Growth?,” American Economic Review, 90(5), 1160-1183.

Blackorby, C., And R. R. Russell (1989): “Will the Real Elasticity of Substitution Please Stand Up? (A Comparison of the Allen-Uzawa and Morishima Elasticities)," American Economic Review, 79(4), 882-888.

Blanchard, O. J. (1985): "Debt, Deficits and Finite Horizons," Journal of Political Economy, 93(2), 223-247.

Blundell, R., AND S. BOND (2000): “GMM Estimation with Persistent Panel Data: An Application to Production Functions," Econometric Reviews, 19(2), 321-340.

Blundell, R., M. C. Dias, And C. Meghir (2003): “The Impact of Wage Subsidies: A General Equilibrium," IFS Working Paper.

Blundell, R., AND T. MACURdy (1999): “Labor Supply: A Review of Alternative Approaches," in Handbook of Labor Economics, ed. by O. Ashenfelter, and D. Card, vol. 3, chap. 27. Elsevier, Amsterdam.

BÖRSCH-SUPAN, A. (2000): "Incentive Effects of Social Security on Labor Force Participation: Evidence in Germany and Across Europe," Journal of Public Economics, 78(1), 25-49.

(2003): “Labor Market Effects of Population Aging," Review of Labor Economics and Industrial Relations, 17(Special Issue), 5-44.

Börsch-Supan, A., A. Ludwig, and J. Winter (2004): “Aging, Pension Reform, and Capital Flows," University of Mannheim MEA Working Paper. 
Börsch-Supan, A., And J. K. Winter (2001): “Population Aging, Savings Behavior, and Capital Markets," NBER Working Paper 8561.

BouCEKKINE, R., D. DE LA CROIX, AND O. LiCANDRO (2002): “Vintage Human Capital, Demographic Trends, and Endogenous Growth," Journal of Economic Theory, 104(2), 340-375.

(2003): "Early Mortality Declines at the Dawn of Modern Growth," Scandinavian Journal of Economics, 105(2), 401-418.

BovenberG, A. L., And T. KnaAp (2005): “Ageing, Funded Pensions and the Dutch Economy," CESifo Working Paper 1403.

Browning, M., L. Hansen, And J. J. Heckman (1999): “Micro Data and General Equilibrium Models," in Handbook of Macroeconomics, ed. by J. Taylor, and M. Woodford, vol. 1, chap. 8. North-Holland, Amsterdam.

Bütler, M., O. Huguenin, And F. Teppa (2004): “What Triggers Early Retirement? Results from Swiss Pension Funds," University of Lausanne deep-HEC Discussion Paper.

CARD, D., AND T. LEMIEUX (2000): “Dropout and Enrollment Trends in the PostWar Period: What Went Wrong in the 1970s?," NBER Working Paper 7658.

Cervellati, M., and U. Sunde (2005): “Human Capital Formation, Life Expectancy and the Process of Development," American Economic Review, 95(5), 1653-1672.

Conesa, J. C., And D. KRueger (1999): “Social Security Reform with Heterogeneous Agents," Review of Economic Dynamics, 2(4), 757-795.

Crémer, H., And P. Pestieau (2003): “The Double Dividend of Postponing Retirement," International Tax and Public Finance, 10(4), 419-434.

Cunha, F., J. J. HeCKMAN, And S. NAVArRo (2005): “Separating Uncertainty from Heterogeneity in Life Cycle Earnings," Oxford Economic Papers, 57(2), 191-261.

DE LA CROIX, D., AND O. LiCANDRO (1999): “Life Expectancy and Endogenous Growth," Economics Letters, 65(2), 255-263. 
Duffy, J., C. Papageorgiou, and F. Perez-Sebastian (2004): “Capital-Skill Complementarity? Evidence from a Panel of Countries," Review of Economics and Statistics, 86(1), 327-344.

Dupor, B., L. Lochner, C. TABer, And M. B. WitTeKind (1996): “Some Effects of Taxes on Schooling and Training," American Economic Review, 86(2), 340-346.

ECHEVARRÍA, C. A. (2004): “Life Expectancy, Schooling Time, Retirement, and Growth," Economic Inquiry, 42(4), 602-617.

FARMeR, R. E. A. (1990): "Rince Preferences," Quarterly Journal of Economics, 105(1), 43-60.

Ferreira, P. C., AND S. DE Abreu PessôA (2005): “The Effects of Longevity and Distortions on Education and Retirement," mimeo.

Galor, O., AND D. N. WeIl (2000): “Population, Technology, and Growth: From Malthusian Stagnation to the Demographic Transition and Beyond," American Economic Review, 90(4), 806-828.

Gertler, M. (1999): “Government Debt and Social Security in a Life-Cycle Economy," Carnegie-Rochester Conference Series on Public Policy, 50, 61-110.

Goldin, C., AND L. KATZ (1998): “The Origins of Technology-Skill Complementarity," Quarterly Journal of Economics, 113(3), 693-732.

Grafenhofer, D., C. JaAg, C. Keuschnigg, and M. Keuschnigg (2005): "Probabilistic Aging," University of St. Gallen Department of Economics Discussion Paper 2005-8.

GRILICHES, Z. (1969): “Capital-Skill Complementarity," Review of Economics and Statistics, 51(4), 465-468.

Gruber, J., AND D. A. WiSE (1999): Social Security and Retirement Around the World. The University of Chicago Press, Chicago.

(2005): "Social Security Programs and Retirement Around the World: Fiscal Implications," NBER Working Paper 11290. 
Guvenen, F. (2003): "Reconciling Conflicting Evidence on the Elasticity of Intertemporal Substitution: A Macroeconomic Perspective," University of Rochester RCER Working Paper 491.

Haley, W. J. (1976): “Estimation of the Earnings Profile from Optimal Human Capital Accumulation," Econometrica, 44(6).

HALL, R. E. (1988): “Intertemporal Substitution in Consumption," Journal of Political Economy, 96(2), 339-357.

Hamermesh, D. S. (1993): Labor Demand. Princeton University Press, Princeton, NJ.

HANSSON, I., And C. StuART (1985): “Tax Revenue and the Marginal Cost of Public Funds in Sweden," Journal of Public Economics, 27(3), 331-353.

Heckman, J. J. (1976): “A Life-Cycle Model of Earnings, Learning, and Consumption," The Journal of Political Economy, 84(4), S11-S44.

HeCKMAn, J. J., And B. E. HonOrÉ (1990): “The Empirical Content of the Roy Model," Econometrica, 58(5), 1121-1149.

Heckman, J. J., L. Lochner, AND C. TABer (1998): “Explaining Rising Wage Inequality: Explorations with a Dynamic General Equilibrium Model of Labor Earnings with Heterogeneous Agents," Review of Economic Dynamics, 1(1), 158.

Huang, R., L. E. Fulginiti, and E. W. F. Peterson (2003): "Investing in Hope: AIDS, Life Expectancy, and Human Capital Accumulation," University of Nebraska-Lincoln Discussion Paper.

İmrohoroĞLU, A., S. İmrohoroĞLU, And D. H. Joines (1995): “A Life Cycle Analysis of Social Security," Economic Theory, 6(1), 83-114.

(1999): “Social Security in an Overlapping Generations Economy with Land," Review of Economic Dynamics, 2(3), 638-665.

JaAG, C., C. KeuschnigG, And M. Keuschnigg (2005): “Skill Formation with Labor Market Frictions," University of St. Gallen IFF Discussion Paper.

JOHNSON, G. E. (1997): “Changes in Earnings Inequality: The Role of Demand Shifts," Journal of Economic Perspectives, 11(2), 41-54. 
Kalemli-Ozcan, S. (2002): "Does the Mortality Decline Promote Economic Growth?," Journal of Economic Growth, 7(4), 411-439.

Kalemli-Ozcan, S., H. E. Ryder, And D. N. Weil (2000): “Mortality Decline, Human Capital Investment, and Economic Growth," Journal of Development Economics, 62(1), 1-23.

KANE, T. J. (1994): “College Entry by Blacks Since 1970: The Role of College Costs, Family Background, and the Returns to Education," Journal of Political Economy, 105(5), 878-911.

KeuschnigG, C., And M. Keuschnigg (2004): “Aging, Labor Markets and Pension Reform in Austria," Finanzarchiv, 60(3), 359-392.

Krusell, P., L. E. Ohanian, J.-V. Rios-Rull, and G. L. Violante (2000): "Capital-Skill Complemetarity and Inequality: A Macroeconomic Analysis," Econometrica, 68(5), 1029-1053.

Kydland, F. E., And E. C. Prescott (1982): “Time to Build and Aggregate Fluctuations," Econometrica, 50(6), 1345-1370.

Laitner, J., And D. Silverman (2005): “Estimating Life-Cycle Parameters from Consumption Behavior at Retirement," NBER Working Paper 11163.

LAU, M. I., AND P. POUtVAaRA (2000): “Social Security Incentives and Human Capital Investment," CEBR Discussion Paper 2000-18.

(2001): “Social Security Rules, Labor Supply and Human Capital Formation," CEBR Discussion Paper 2001-10.

Lechner, M., And R. VazQuez-Alvarez (2005): “Modelling Active Labour Market Policies in a Life-Cycle Model of Labour Participation and Human Capital Formation," University of St. Gallen SIAW Discussion Paper.

LINDQUiST, M. J. (2004): “Capital-Skill Complementarity and Inequality over the Business Cycle," Review of Economic Dynamics, 7(3), 519-540.

LORD, W. (1989): “The Transition from Payroll to Consumption Receipts with Endogenous Human Capital," Journal of Public Economics, 38(1), 53-73.

LuCAS, R. E. (1990): “Supply-Side Economics: An Analytical Review," Oxford Economic Papers, 42(2), 293-316. 
Martín, A. R. S. (2003): “Endogenous Retirement and Public Pension System Reform in Spain," Cebtro Atlántico de Estudios Ríos Pérez Working Paper 17.

Miles, D. (1999): "Modelling the Impact of Demographic Change Upon the Economy," Economic Journal, 109(452), 1-36.

Mincer, J. A. (1974): Schooling, Experience and Earnings. Columbia University Press, New York.

(1991): “Job Training: Costs, Returns, and Wage Profiles," in Market Failure in Training?, ed. by D. Stern, and J. M. Ritzen. Springer, Berlin.

(1997): “The Production of Human Capital and the Life Cycle of Earnings: Variations on a Theme," Journal of Labor Economics, 15(1), S26-S47.

Mitchell, O. S., AND J. W. Phillips (2000): "Retirement Responses to Early Social Security Benefit Reductions," NBER Working Paper 7963.

Papageorgiou, C., And V. Chmelarova (2005): "Nonlinearities in CapitalSkill Complementarity," Journal of Economic Growth, 33(1), 59-89.

Perroni, C. (1995): “Assessing the Dynamic Efficiency Gains of Tax Reform When Human Capital is Endogenous," International Economic Review, 36(4), 907-925.

RAMSeY, F. (1928): “A Mathematical Theory of Saving," Economic Journal, 38(152), 534-559.

RAZIN, A., AND E. SADKA (2001): Labor, Capital, and Finance: International Flows. Cambridge University Press, Cambridge.

RojAS, J. A. (2005): “Life-Cycle Earnings, Cohort Size Effects and Social Security: A Quantitative Exploration," Journal of Public Economics, 89(2-3), 465-485.

RoY, A. (1951): "Some Thoughts on the Distribution of Earnings," Oxford Economic Papers, 3(2), 135-146.

SATO, K. (1967): “A Two-Level Constant-Elasticity-of-Substitution Production Function," Review of Economic Studies, 34(2), 201-218.

SoARES, R. R. (2005): “Mortality Reductions, Educational Attainment, and Fertility Choice," American Economic Review, 95(3), 580-601. 
SWANSON, C. E., AND K. J. Kopecky (1999): “Lifespan and Output,” Economic Inquiry, 37(2), 213-225.

Topel, R. (1999): "Labor Markets and Economic Growth," in Handbook of Labor Economics, ed. by O. Ashenfelter, and D. Card, vol. 3, chap. 44, pp. 2943-2984. Elsevier, Amsterdam.

Weil, P. (1989): “The Equity Premium Puzzle and the Risk-Free Rate Puzzle," Journal of Monetary Economics, 24(3), 401-421.

(1990): “Nonexpected Utility in Macroeconomics," Quarterly Journal of Economics, 105(1), 29-42.

WEISS, Y. (1986): “The Determinants of Life Cycle Earnings: A Survey," in Handbook of Labor Economics, ed. by O. Ashenfelter, and R. Layard, vol. I, chap. 11, pp. 603-639. Elsevier, Amsterdam.

Willis, R. J., AND S. Rosen (1979): “Education and Self-Selection," Journal of Political Economy, 87(5), 7-36. 